Nicolaou, M., Papanikolaou, M., Tsipis, A., Kabanos, T., Keramidas, A., Sproules, S. and Miras, H. N. (2018) Design and assembly of covalently functionalised polyoxofluorovanadate molecular hybrids. Chemistry: A European Journal, 24(15), pp. 3836-3845. (doi:10.1002/chem.201705730)

There may be differences between this version and the published version. You are advised to consult the publisher's version if you wish to cite from it.

This is the peer-reviewed version of the following article: Nicolaou, M., Papanikolaou, M., Tsipis, A., Kabanos, T., Keramidas, A., Sproules, S. and Miras, H. N. (2018) Design and assembly of covalently functionalised polyoxofluorovanadate molecular hybrids. Chemistry: A European Journal, 24(15), pp. 3836-3845, which has been published in final form at 10.1002/chem.201705730. This article may be used for non-commercial purposes in accordance with Wiley Terms and Conditions for Self-Archiving.

\title{
http://eprints.gla.ac.uk/155210/
}

Deposited on 12 January 2018

Enlighten - Research publications by members of the University of Glasgow http://eprints.gla.ac.uk 


\section{Design and Assembly of Covalently Functionalized Polyoxofluorovanadate Molecular Hybrids}

Maria Nicolaou, ${ }^{[a]}$ Michael G. Papanikolaou, ${ }^{[b]}$ Athanassios C. Tsipis, ${ }^{[b]}$ Themistoklis A.

Kabanos, ${ }^{*[\mathrm{~b}]}$ Anastasios D. Keramidas, ${ }^{*[\mathrm{a}]}$ Stephen Sproules, ${ }^{*[\mathrm{c}]}$ and Haralampos N. Miras ${ }^{*[\mathrm{c}]}$

[a] M. Nicolaou, Dr. A. D. Keramidas

Department of Agricultural Production Biotechnology and Food Science

Cyprus University of Technology

3036 Limassol (Cyprus)

Email: akeramid@ucy.ac.cy

[b] M. G. Papanikolaou, Dr. A. C. Tsipis, Prof. T. A. Kabanos

Section of Inorganic and Analytical Chemistry

Department of Chemistry, University of Ioannina

45110 Ioannina (Greece)

Email: attsipis@uoi.gr, tkampano@cc.uoi.gr

[c] Dr. S. Sproules, Dr. H. N. Miras

WestCHEM, School of Chemistry, University of Glasgow

Glasgow G12 8QQ (UK)

Email: stephen.sproules@glasgow.ac.uk, charalampos.moiras@glasgow.ac.uk 
Abstract. Mixed-valent polyoxometalate (POM) clusters are one of the most interesting host species showing a wide range of structural features and properties. We report the facile preparation and functionalization of a mixed-valent polyoxofluorovanadates where two electrons are trapped to antipodal sites of the clusters. The first members of this family of clusters with the general formula, $\left[\mathrm{V}_{12}{ }_{12} \mathrm{~V}^{\mathrm{IV}}{ }_{2} \mathrm{O}_{16}(\mu-\mathrm{O})_{10}\left(\mu_{3}-\mathrm{O}\right)_{10}\left(\mu_{3}-\mathrm{F}\right)_{2}(\mathrm{~L})_{2}\right]^{6-}$, where $\mathrm{L}$ : py = pyridine $(\mathbf{1})$; pyr = pyrazine (2); im = imidazole (3), are unique organic-inorganic hybrids with the addition of a $\mathrm{N}$ donor ligand at either end of the polyoxofluorovanadate. The composition and connectivity of $\mathbf{1}$ - 3 were characterized by single-crystal X-ray diffractometry and electrospray ionization mass spectrometry. Electron paramagnetic resonance spectroscopy revealed the two well-separated $\mathrm{V}^{\mathrm{IV}}$ ions in each cluster are fully uncoupled with $J=0$ giving a degenerate singlet-triplet ground state. This attenuation of the exchange interaction is probed with density functional theoretical calculations that detail the inclusion of the fluoride ion in the cluster produces a bond pathway biased toward destructive interference between competing ferromagnetic and antiferromagnetic interactions. These robust molecular materials are the ideal combination of desirable electronic properties with an organic handle with which they can be integrated into spintronic circuitry for molecular devices. 


\section{Introduction}

Polyoxometalate chemistry has attracted the interest of various research groups due to its aesthetically appealing structural features and wide-ranging properties with applications in catalysis, coatings, pigments, smart materials, luminescence, electrochemistry, biochemistry, and medicine. ${ }^{[1]}$ Within the large polyoxometalate family, which is mainly constructed by vanadium, molybdenum and tungsten centers in their high oxidation states, mixed-valent polyoxovanadates clusters, are one of the most interesting subgroups due to their complex equilibria of numerous species and rich redox chemistry which is reflected to unique catalytic properties, magnetic behaviour and energy storage applications. ${ }^{[2-6]}$ The assembly of vanadate clusters in aqueous medium has been studied extensively, and the reported structures include a wide range of nuclearities and structural motifs such as $\left[\mathrm{V}_{3} \mathrm{O}_{9}\right]^{3-},\left[\mathrm{V}_{5} \mathrm{O}_{14}\right]^{3-},\left[\mathrm{V}_{8} \mathrm{O}_{14}\right]^{4-},\left[\mathrm{V}_{12} \mathrm{O}_{32}\right]^{4-},\left[\mathrm{V}_{13} \mathrm{O}_{34}\right]^{3-}$, $\left[\mathrm{V}_{15} \mathrm{O}_{42}\right]^{9-},\left[\mathrm{H}_{2} \mathrm{~V}_{16} \mathrm{O}_{39}\right]^{7-}$ and $\left[\mathrm{V}_{34} \mathrm{O}_{82}\right]^{10-} \cdot{ }^{[7,8]}$ Most of these clusters exhibit the closed sphere-like structures, ${ }^{[8-10]}$ and only $\left[\mathrm{V}_{12} \mathrm{O}_{32}\right]^{4-}$ has an open, bowl-shaped framework that can act as a host. ${ }^{[11]}$ An intriguing subcategory of the polyoxovanadate species is the family of polyoxofluorovanadate clusters which is the result of fluoride incorporation into the metal oxide shell, and substitutes one or more oxygen centers from the vanadium coordination sphere. The consequences of this incorporation are quite important due to changes in both the charge of the oxofluorovanadium subunits as well as the composition of the cluster. ${ }^{[12]}$ Moreover, the differences in bridging modes induced by the fluoride incorporation as well as the coordination requirements of the $\left[\mathrm{MO}_{x} \mathrm{~F}_{y}\right]$ and $\left[\mathrm{MO}_{x+y}\right]$ units affect the formation and stability of different building block libraries as well as the speciation of the vanadium species in aqueous media. Another noteworthy feature of oxofluorovanadates is their preference for slightly less electropositive metal centers, e.g. $\mathrm{V}^{\mathrm{IV}}$ instead of $\mathrm{V}^{\mathrm{V}}$, which is due to the high electronegativity of 
the fluoride ion. The consequence of the introduced characteristics, gives rise to interesting physical properties such as magnetism, ${ }^{[6]}$ catalysis, ${ }^{[13]}$ and non-linear optical activity. ${ }^{[14]}$ An interesting observation of the vanadium fluoride and oxofluoride chemistry is the tendency for polymerization and formation of products which exhibit 2D and 3D structures constructed by oligomeric, chain and ladder shaped building blocks. ${ }^{[2,5,15,16]}$ Moreover, the formation of these structures has been achieved under hydrothermal conditions which is known for the complexity of this reaction domain, ${ }^{[15,17]}$ and the associated inherent difficulties in understanding the assembly process. Interestingly, the reported higher nuclearity molecular polyoxofluorometalates are quite rare. Previous exploration of the polyoxofluorometalate systems led to the discovery of compounds which are mainly limited to monomers and low nuclearity species..$^{[4,12,18]}$

Herein, we present the one-pot synthesis and characterization of three mixed-valent, functionalized polyoxofluorovanadate organic-inorganic hybrids: $[p y \mathrm{H}]_{6}\left[\mathrm{~V}_{12}^{\mathrm{V}} \mathrm{V}^{\mathrm{IV}}{ }_{2} \mathrm{O}_{16}(\mu-\mathrm{O})_{10}\left(\mu_{3^{-}}\right.\right.$ $\left.\mathrm{O})_{10}\left(\mu_{3}-\mathrm{F}\right)_{2}(\mathrm{py})_{2}\right] \cdot 10 \mathrm{H}_{2} \mathrm{O} \quad$ (1), $\quad[\mathrm{pyH}]_{6}\left[\mathrm{~V}^{\mathrm{V}_{12}} \mathrm{~V}^{\mathrm{IV}}{ }_{2} \mathrm{O}_{16}(\mu-\mathrm{O})_{10}\left(\mu_{3}-\mathrm{O}\right)_{10}\left(\mu_{3}-\mathrm{F}\right)_{2}(\mathrm{pyr})_{2}\right] \quad$ (2), and $[\mathrm{imH}]_{6}\left[\left(\mathrm{~V}^{\mathrm{V}}{ }_{12} \mathrm{~V}^{\mathrm{IV}}{ }_{2} \mathrm{O}_{16}(\mu-\mathrm{O})_{10}\left(\mu_{3}-\mathrm{O}\right)_{10}\left(\mu_{3}-\mathrm{F}\right)_{2}(\mathrm{im})_{2}\right] \cdot 2 \mathrm{H}_{2} \mathrm{O}(3)\right.$, where py = pyridine; pyr = pyrazine and $\mathrm{im}=$ imidazole, encapsulating two fluoride ions within the structure and covalently functionalized with a series of nitrogen donor ligands under mild conditions. The compounds were characterized in solid state by X-ray analysis, thermogravimetric analysis (TGA), infrared spectroscopy (FT-IR) as well as in solution by electrospray ionization mass spectrometry (ESIMS) and electron paramagnetic resonance (EPR). Investigation of the electronic state of this family of clusters using EPR in combination with density functional theoretical (DFT) calculations revealed the lack of communication between the isolated $\mathrm{V}^{\mathrm{IV}}$ centers. Additionally, these clusters are the first examples of high nuclearity derivatized polyoxofluorovanadates. This detailed examination of the electronic structure of this series in concert with the new facile 
functionalization approach reveals the great potential for further development of molecular materials for spintronic devices. ${ }^{[19]}$
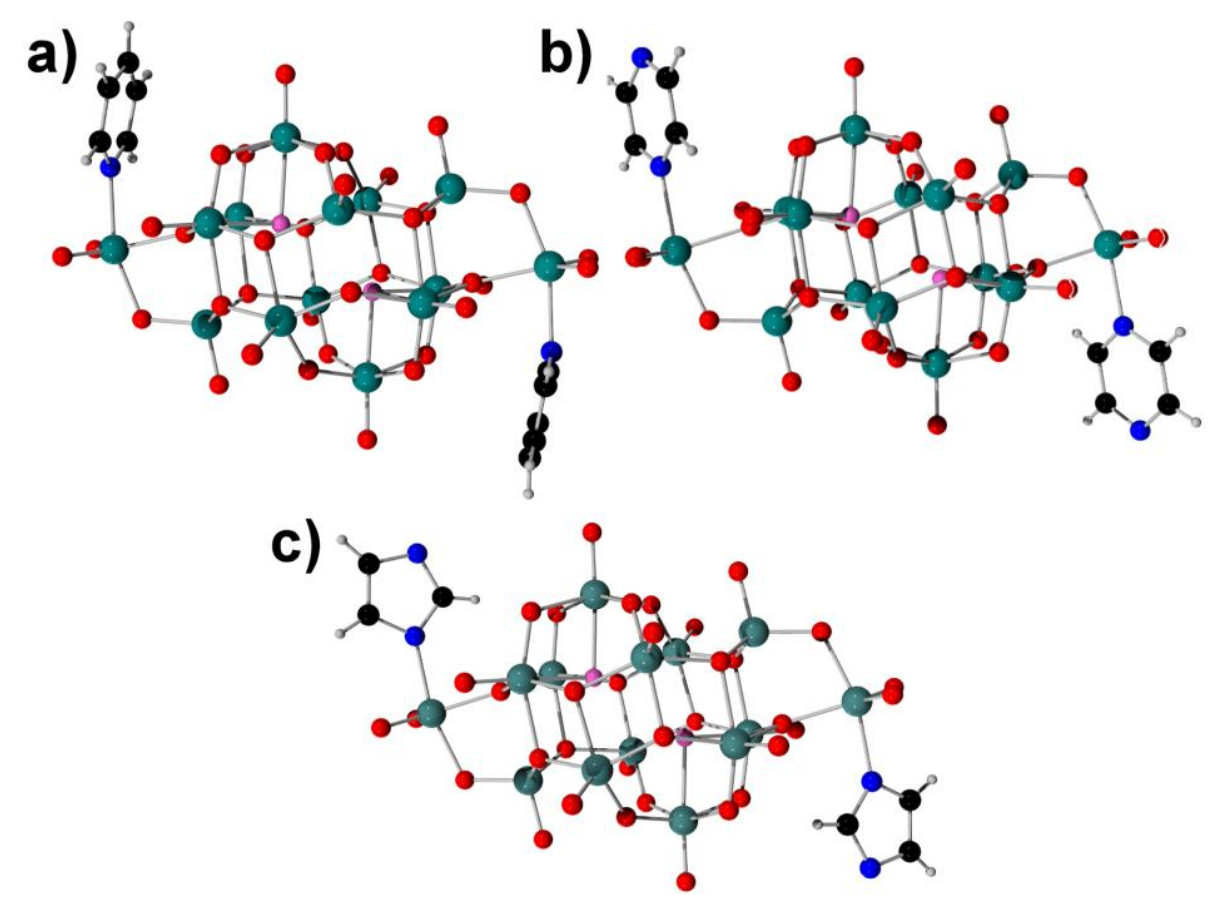

Figure 1. Structures of the anions in crystals of (a) 1, (b) $\mathbf{2}$ and (c) $\mathbf{3}$ (color code: V, teal; O, red; F, pink; C, black; N, blue; H: light grey. Counterions and lattice solvent have been omitted for clarity.

\section{Experimental Section}

Materials. The chemicals and solvents were purchased from Sigma-Aldrich and Alfa Aesar and used without further purification. All solvents were analytical reagent grade and used without further purification. $\mathrm{VOSO}_{4} \cdot 3 \mathrm{H}_{2} \mathrm{O}$ was prepared by reacting $\mathrm{V}_{2} \mathrm{O}_{5}$ with $\mathrm{H}_{2} \mathrm{SO}_{4}$ using ethanol as reductant. The compounds $[\mathrm{pyH}]_{2}\left[\mathrm{~V}^{\mathrm{IV}}{ }_{2} \mathrm{O}_{2} \mathrm{~F}_{4}(\mu-\mathrm{F})_{2}\left(\mathrm{OH}_{2}\right)_{2}\right]$ (py = pyridine), $[\mathrm{imH}]_{2}\left[\mathrm{~V}^{\mathrm{IV}}{ }_{2} \mathrm{O}_{2} \mathrm{~F}_{4}(\mu-\right.$ $\left.\mathrm{F})_{2}\left(\mathrm{OH}_{2}\right)_{2}\right]$ (im = imidazole) and $\left[\mathrm{Et}_{3} \mathrm{NH}\right]_{2}\left[\mathrm{~V}^{\mathrm{IV}}{ }_{2} \mathrm{O}_{2} \mathrm{~F}_{4}(\mu-\mathrm{F})_{2}\left(\mathrm{OH}_{2}\right)_{2}\right]$ were prepared according to 
the literature. ${ }^{[20]}$ Caution! Hydrofluoric acid is both toxic and corrosive and must be handled with extreme caution and with the appropriate protective gear! If contact with the liquid or vapor occurs, proper treatment procedures should be followed immediately. ${ }^{[21]}$

\section{$[p y H]_{6}\left[\mathrm{~V}^{\mathrm{V}_{12}} \mathrm{~V}^{\mathrm{IV}} \mathbf{2}_{16}(\mu-\mathrm{O})_{10}(\mu 3-\mathrm{O})_{10}(\mu 3-\mathrm{F})_{2}(\mathbf{p y})_{2}\right] \cdot \mathbf{1 0 H}_{2} \mathrm{O} \quad(\mathbf{1}) . \quad[\mathrm{pyH}]_{2}\left[\mathrm{~V}^{\mathrm{IV}}{ }_{2} \mathrm{O}_{2} \mathrm{~F}_{4}(\mu-\mathrm{F})_{2}\left(\mathrm{OH}_{2}\right)_{2}\right]$} $(0.300 \mathrm{~g}, 0.676 \mathrm{mmol})$ was dissolved in $3.0 \mathrm{~mL}$ of water $(\mathrm{pH} \approx 3)$ and to the stirred solution was added pyridine $0.23 \mathrm{~mL}(0.22 \mathrm{~g}, 2.8 \mathrm{mmol})(\mathrm{pH} \approx 4)$. The solution was left undisturbed at room temperature $\left(\sim 18{ }^{\circ} \mathrm{C}\right)$ for 2 weeks during which diffraction-quality crystals were collected by filtration, washed with water $(2 \times 1 \mathrm{~mL})$ and dried under vacuum. Yield: $0.050 \mathrm{~g}$ ( $24 \%$ based on V). Anal. Calcd for $\mathrm{C}_{40} \mathrm{H}_{66} \mathrm{~F}_{2} \mathrm{~N}_{8} \mathrm{O}_{46} \mathrm{~V}_{14}\left(M_{\mathrm{r}}=2145.15 \mathrm{~g} \mathrm{~mol}^{-1}\right)$ : C, 22.37; H, 3.05; F, 1.77; N, 5.22; V, 33.24. Found: C, 22.43; H, 2.33; F, 1.75; N, 5.12; V, 32.85. IR $\left(\mathrm{KBr}, \mathrm{cm}^{-1}\right): 3451 \mathrm{w},[-$ $\mathrm{OH}] ; 3131 \mathrm{w},[\mathrm{N}-\mathrm{H}] ; 1618 \mathrm{~m},\left[\mathrm{H}_{2} \mathrm{O}\right] ; 1463 \mathrm{~s},[v$ ring]; $1058 \mathrm{~m}, 951 \mathrm{~s},[\mathrm{~V}=\mathrm{O}] ; 853 \mathrm{~s},[\mathrm{~V}-\mathrm{O}-\mathrm{V}]$; $805 \mathrm{~s},[\mathrm{~V}-\mathrm{O}-\mathrm{V}] ; 774 \mathrm{~m},[v$ ring]; $583 \mathrm{~s}$ [V-F].

$[\mathbf{p y H}]_{6}\left[\mathbf{V}^{\mathrm{V}_{12}} \mathbf{V}^{\mathrm{IV}_{2}} \mathrm{O}_{\mathbf{1 6}}(\boldsymbol{\mu} \text {-O })_{10}(\boldsymbol{\mu} \mathbf{3}-\mathrm{O})_{\mathbf{1 0}}(\boldsymbol{\mu} \mathbf{3}-\mathbf{F})_{\mathbf{2}}(\mathbf{p y r})_{2}\right]$ (2). $[\mathrm{pyH}]_{2}\left[\mathrm{~V}^{\mathrm{IV}}{ }_{2} \mathrm{O}_{2} \mathrm{~F}_{4}(\mu-\mathrm{F})_{2}\left(\mathrm{OH}_{2}\right)_{2}\right](0.200 \mathrm{~g}$, $0.450 \mathrm{mmol})$ dissolved in $\mathrm{H}_{2} \mathrm{O}(1 \mathrm{~mL})$. Pyrazine $(0.078 \mathrm{~g}, 0.974 \mathrm{mmol})$ was added directly to the above solution under continuous stirring. The blue solution was left at room temperature ( 18 ${ }^{\circ} \mathrm{C}$ ) for 4 weeks during which period the color of the reaction mixture turned green producing dark green single crystals which were collected by filtration, washed with water $(2 \times 1 \mathrm{~mL})$ and dried under vacuum. Yield: $0.042 \mathrm{~g}$ ( $33 \%$ based on V). Anal. Calcd for $\mathrm{C}_{38} \mathrm{H}_{44} \mathrm{~F}_{2} \mathrm{~N}_{10} \mathrm{O}_{36} \mathrm{~V}_{14}\left(M_{\mathrm{r}}=\right.$ $1967.61 \mathrm{~g} \mathrm{~mol}^{-1}$ ): C, 23.19; H, F, 1.93; 2.25; N, 7.12; V, 36.25. Found: C, 23.02; H, 2.45; F, 1.89; N, 7.10; V, 36.20. IR (KBr, cm $\left.{ }^{-1}\right): 3398 \mathrm{~m}, 3124 \mathrm{~m},[\mathrm{~N}-\mathrm{H}] ; 1718 \mathrm{~s}, 1483 \mathrm{~s},[v$ ring]; $1400 \mathrm{~s}$, [ $v$ ring]; $970 \mathrm{~s},[\mathrm{~V}=\mathrm{O}] ; 758 \mathrm{~s}[v$ ring]; $579 \mathrm{~m}$ [V-F]. 
$[\mathrm{imH}]_{6}\left[\mathrm{~V}^{\mathrm{V}_{12}} \mathrm{~V}^{\mathrm{IV}} \mathbf{2}_{2} \mathrm{O}_{16}(\boldsymbol{\mu}-\mathrm{O})_{10}\left(\boldsymbol{\mu}_{3}-\mathrm{O}\right)_{10}\left(\boldsymbol{\mu}_{3}-\mathrm{F}\right)_{2}(\mathrm{im})_{2}\right] \cdot \mathbf{2} \mathrm{H}_{2} \mathrm{O} \quad(\mathbf{3}) . \quad[\mathrm{imH}]_{2}\left[\mathrm{~V}^{\mathrm{IV}}{ }_{2} \mathrm{O}_{2} \mathrm{~F}_{4}(\mu-\mathrm{F})_{2}\left(\mathrm{OH}_{2}\right)_{2}\right]$ (0.200 g, $0.474 \mathrm{mmol})$ dissolved in $\mathrm{H}_{2} \mathrm{O}(1 \mathrm{~mL})$. The blue solution was left at room temperature $\left(\sim 18{ }^{\circ} \mathrm{C}\right)$ for 4 weeks during which period the color of the reaction mixture turned green from which dark blue single crystals were collected by filtration, washed with water $(2 \times 1 \mathrm{~mL})$ and dried under vacuum. Yield: $0.045 \mathrm{~g}\left(32 \%\right.$ based on V). Anal. Calcd for $\mathrm{C}_{24} \mathrm{H}_{42} \mathrm{~F}_{2} \mathrm{~N}_{16} \mathrm{O}_{38} \mathrm{~V}_{14}\left(M_{\mathrm{r}}=\right.$ $\left.1913.62 \mathrm{~g} \mathrm{~mol}^{-1}\right): \mathrm{C}, 15.05 ; \mathrm{H}, 2.21 ; \mathrm{F}, 1.98 ; \mathrm{N}, 11.71 ; \mathrm{V}, 37.27$. Found: C, 15.15; H, 2.22; F, 1.88; N, 11.25; V, 37.17. IR $\left(\mathrm{KBr}, \mathrm{cm}^{-1}\right): 3126 \mathrm{~s},[\mathrm{~N}-\mathrm{H}] ; 1722 \mathrm{~s}, 1587 \mathrm{~m}, 1400 \mathrm{~s},[v$ ring]; $974 \mathrm{~s}$, [V=O]; $765 \mathrm{w},[\mathrm{V}-\mathrm{O}-\mathrm{V}] ; 686 \mathrm{w},[v$ ring]; $626 \mathrm{~m}[\mathrm{~V}-\mathrm{F}]$.

\section{X-Ray Crystallographic Data Collection and Refinement of the Compounds. Suitable} single crystals were selected and mounted onto a rubber loop using Fomblin oil. Single-crystal X-ray diffraction data of $\left[\mathrm{Et}_{3} \mathrm{NH}\right]_{2}\left[\mathrm{~V}^{\mathrm{IV}}{ }_{2} \mathrm{O}_{2} \mathrm{~F}_{4}(\mu-\mathrm{F})_{2}\left(\mathrm{OH}_{2}\right)_{2}\right]$, and $\mathbf{1}-\mathbf{3}$ were recorded on a XCaliburSuperNova 4-cycle diffractometer, using $\mathrm{Cu}(\lambda=1.54184 \AA)$ and $\mathrm{Mo}\left(\lambda\left(\mathrm{MoK}_{\alpha}\right)=\right.$ $0.71073 \AA$ A) radiation at $150 \mathrm{~K}$ equipped with a CCD camera detector. Structure solution and refinement were carried out with SHELXS-97 ${ }^{[22]}$ and SHELXL-97 ${ }^{[23]}$ using the WinGX ${ }^{[24]}$ software package. Corrections for incident and diffracted beam absorption effects were applied using empirical absorption corrections. ${ }^{[25]}$ All the atoms were refined anisotropically. Even though the identification of $\mathrm{O}$ and $\mathrm{F}$ atoms can occasionally be problematic, the absence of disorder as well as the small $\mathrm{R}$ factor allowed us to determine unambiguously the positions occupied by $\mathrm{O}$ and $\mathrm{F}$ atoms. Additionally, we evaluated the refinement of the structures by assigning either $\mathrm{O}$ or $\mathrm{F}$ atoms. Additionally, the determination of the solvent content was based on the TGA analysis performed on freshly prepared samples, see ESI (Figures S9-S11). Final 
unit cell data and refinement statistics for the compounds $\mathbf{1}-\mathbf{3}$ are collated in Table S1. Crystallographic data for all compounds (CCDC 1580654-1580656, 1582345) can be obtained free of charge from the Cambridge Crystallographic Data Centre, 12, Union Road, Cambridge CB2 1EZ; fax:(+44) 1223- 336-033, deposit@ccdc.cam.ac.uk.

Physical Measurements. IR spectra were measured using JASCO FTIR 410 and Shimadzu FTIR 8400S spectrometers. Thermogravimetric analysis was performed on a TA Instruments Q 500 thermogravimetric analyzer under nitrogen flow at a typical heating rate of $10{ }^{\circ} \mathrm{C} \mathrm{min}^{-1}$ in a platinum pan. Electrospray ionization mass spectrometry was performed using a Bruker micrOTOF-Q quadrupole time-of-flight mass spectrometer. Samples were dissolved in water and $\mathrm{MeCN}$ introduced at a dry gas temperature of $180^{\circ} \mathrm{C}$. The ion polarity for all MS scans recorded was negative, with the voltage of the capillary tip set at $4500 \mathrm{~V}$, end plate offset at $-500 \mathrm{~V}$, funnel $1 \mathrm{RF}$ at $400 \mathrm{Vpp}$ and funnel $2 \mathrm{RF}$ at $400 \mathrm{Vpp}$, hexapole RF at $200 \mathrm{Vpp}$, ion energy 5.0 $\mathrm{eV}$, collision energy at $15 \mathrm{eV}$, collision cell RF at $1200 \mathrm{Vpp}$, transfer time at $120.0 \mu$ s, the prepulse storage time at $20.0 \mu$ s and analysed using the Bruker Daltonics v4.1 software. X-band EPR spectra were recorded on a Bruker ELEXSYS E500 spectrometer and simulations performed using Xsophe. ${ }^{[26]}$ Elemental analyses were determined by the in-house microanalysis services using an EA 1110 CHNS, CE-440 Elemental Analyzer. Flame atomic absorption spectroscopy analysis was performed with a Perkin-Elmer 1100B atomic absorption spectrophotometer and ICP-OES. The fluoride content was analyzed gravimetrically as $\mathrm{PbClF}^{[27]}$ 
Calculations. All calculations in this work were performed with the electronic structure program ORCA. ${ }^{[28]}$ Electronic structure of $\mathbf{1}$ was calculated on the crystallographic coordinates at the B3LYP level of theory. ${ }^{[29]}$ A segmented all-electron relativistically contracted (SARC) basis set of triple- $\zeta$-quality (def2-TZVP) was used for all atoms. ${ }^{[30]}$ Core electrons were kept frozen and described by single Slater functions (core shells: C, N, O, F, 1s; V, 1s2p). A scalar relativistic correction was applied using the zeroth-order regular approximation (ZORA) method. ${ }^{[31]}$ An allelectron polarized triple- $\zeta$-quality (def2-TZVP) basis set of the Ahlrichs' group was used for the other atoms. ${ }^{[32]}$ Auxiliary basis sets for all complexes used to expand the electron density in the calculations were chosen to match the orbital basis. The conductor like screening model $(\mathrm{COSMO})^{[33]}$ was used for all calculations to account for solvent effects (water, $\varepsilon=80.4$ ). The solvent cavity around the surrounding the compounds was generated with a solvent-excluding surface based on the ionic radii of the surface atoms defined as $0.68 \AA$ for vanadium, $1.47 \AA$ for fluorine, $1.52 \AA$ for oxygen, $1.55 \AA$ for nitrogen, $1.70 \AA$ for carbon, $1.20 \AA$ for hydrogen. A spinunrestricted formulism was applied to all species. The self-consistent field (SCF) calculations were tightly converged $\left(1 \times 10^{-8} E_{\mathrm{h}}\right.$ in energy, $1 \times 10^{-7} E_{\mathrm{h}}$ in the density change, and $1 \times 10^{-7}$ in the maximum element of the DIIS error vector). The geometry search for all complexes was carried out in redundant internal coordinates without imposing geometry constraints. The exchange coupling constant, $J$ was calculated on a broken-symmetry ${ }^{[34]}$ solution using Eq. $1,^{[35]}$ and assuming the spin-Hamiltonian Eq. 2 is valid.

$$
\begin{aligned}
& J=\frac{E_{H S}-E_{B S}}{\left\langle\hat{S}^{2}\right\rangle_{H S}-\left\langle\hat{S}^{2}\right\rangle_{B S}} \\
& \hat{H}=-2 J \hat{S}_{\mathrm{A}} \cdot \hat{S}_{\mathrm{B}}
\end{aligned}
$$


Canonical orbitals and spin density plots were constructed using the program Molekel. ${ }^{[36]}$ Natural atomic orbital $(\mathrm{NAO})$ and natural bond orbital $(\mathrm{NBO})^{[37]}$ population analyses were calculated on the $\left[\mathrm{V}_{14} \mathrm{O}_{36} \mathrm{~F}_{2}\right]^{6-}$ cluster using the Gaussian 09 program ${ }^{[38]}$ at the M062X/DGDZVP level of theory. ${ }^{[39]}$ Nucleus-Independent Chemical Shifts (NICS) values were computed at the B3LYP/LANL2DZ level according to the procedure described by Schleyer et $a l{ }^{[40]}$ The magnetic shielding tensor element was calculated for a ghost atom located at the center of the ring and along the $z$-axis from -5 to $5 \AA$ at $0.5 \AA$ increments. The $\mathrm{V}-\mathrm{F}$ bond was described by the Atoms In Molecules (AIM) method as implemented in Multiwfn 3.3.7 software. $^{[41]}$

\section{Results and Discussion}

Synthesis. The employed synthetic procedure for the preparation of this new family of mixedvalent $\left\{\mathrm{V}_{14}\right\}$ clusters involves the utilization of the binuclear oxofluorovanadate species, $\left[\mathrm{V}^{\mathrm{IV}}{ }_{2} \mathrm{O}_{2} \mathrm{~F}_{4}(\mu-\mathrm{F})_{2}\left(\mathrm{OH}_{2}\right)_{2}\right]^{2-}$. Three divanadium(IV) complexes were prepared. Two were isolated as pyridinium $\left(\mathrm{pyH}^{+}\right)$and imidazolium $\left(\mathrm{imH}^{+}\right)$salts that were precursors for the $\left\{\mathrm{V}_{14}\right\}$ clusters $\mathbf{1}$

- 3. The structure of the $[\mathrm{pyH}]_{2}\left[\mathrm{~V}^{\mathrm{IV}}{ }_{2} \mathrm{O}_{2} \mathrm{~F}_{4}(\mu-\mathrm{F})_{2}\left(\mathrm{OH}_{2}\right)_{2}\right]$ and $[\mathrm{im}]_{2}\left[\mathrm{~V}^{\mathrm{IV}}{ }_{2} \mathrm{O}_{2} \mathrm{~F}_{4}(\mu-\mathrm{F})_{2}\left(\mathrm{OH}_{2}\right)_{2}\right]$ binuclear species were confirmed with the solid-state characterization of $\left[\mathrm{Et}_{3} \mathrm{NH}\right]_{2}\left[\mathrm{~V}^{\mathrm{IV}_{2}} \mathrm{O}_{2} \mathrm{~F}_{4}(\mu\right.$ $\left.\mathrm{F})_{2}\left(\mathrm{OH}_{2}\right)_{2}\right]$ as an edge-sharing bioctahedron (Figure S1). The X-band EPR spectra of the binuclear species show in frozen aqueous solution a broad unresolved signal due to the $\mathrm{V}^{\mathrm{IV}}-\mathrm{V}^{\mathrm{IV}}$ spin interactions (Figure S2). Additionally, in frozen dimethyl sulfoxide (DMSO) the X-band EPR spectra gave a signal indicative of a mononuclear oxovanadium(IV) species, $\left[\mathrm{V}^{\mathrm{IV}} \mathrm{OF}_{3}(\mathrm{DMSO})\right]^{-}$(Figures S3 and S4). ${ }^{[42]}$

The synthesis of the $\left\{\mathrm{V}_{14}\right\}$ cluster $\mathbf{1}$ is described in Eq. 3: 
$7[p y H]_{2}\left[\mathrm{~V}^{\mathrm{IV}}{ }_{2} \mathrm{O}_{2} \mathrm{~F}_{4}(\mu-\mathrm{F})_{2}\left(\mathrm{OH}_{2}\right)_{2}\right]+34 \mathrm{py}+3 \mathrm{O}_{2}+12 \mathrm{H}_{2} \mathrm{O} \rightarrow \mathbf{1}+40[\mathrm{pyH}] \mathrm{F}+4 \mathrm{H}_{2} \mathrm{O}$

The covalent grafting of organic molecules using a series of $\mathrm{N}$-donor ligands (py, pyr, im) during the initial stages of the reaction, proved to be crucial for the formation of the first examples of functionalized $\left\{\mathrm{V}_{14}\right\}$ clusters, and their crystallization in a pure form. In general, efforts to functionalize pre-formed polyoxometalate species using $\mathrm{N}$-donor ligands leads to side reactions which give rise to a variety of species and different extend of fucntionalization. ${ }^{[43]}$ The second stage of the reaction is governed by a redox driven self-assembly process, ${ }^{[44]}$ during which the partial oxidation of the vanadium(IV) centers resulted in a suite of secondary building blocks and different coordination geometries ranging from octahedral to tetrahedral, square pyramidal and trigonal bipyramidal.

The diversity of geometries observed in polyoxovanadate chemistry is mainly based on the inherent tendency of vanadium-based building blocks for electrostatic stabilization which promotes the formation of species with a lower number of oxygen ligands in an effort to compensate the overall negative charge introduced by oxo groups. ${ }^{[3,10]}$ In this case, slow oxidation of the aqueous solution of $\left[\mathrm{V}^{\mathrm{IV}}{ }_{2} \mathrm{O}_{2} \mathrm{~F}_{4}(\mu-\mathrm{F})_{2}\left(\mathrm{OH}_{2}\right)_{2}\right]^{2-}$ by air in the presence of N-donor ligands at $\mathrm{pH} \approx 3$ resulted in the formation of dark blue crystals of the first family of functionalized polyoxofluorovanadates with the general formula, $\left[\mathrm{V}^{\mathrm{V}}{ }_{12} \mathrm{~V}^{\mathrm{IV}}{ }_{2} \mathrm{O}_{16}(\mu-\mathrm{O})_{10}\left(\mu_{3^{-}}\right.\right.$ $\left.\mathrm{O})_{10}\left(\mu_{3}-\mathrm{F}\right)_{2}(\mathrm{~L})_{2}\right]^{6-}(\mathrm{L}=$ py, pyr, im for $\mathbf{1}, \mathbf{2}$ and 3, respectively; Figure 1$)$. The observed reactivity of the $\mathrm{N}$-donor ligands under the experimental conditions revealed the following trend, pyr > py $>\mathrm{im}$, which is in agreement with the $\mathrm{p} K_{\mathrm{a}}$ value of their conjugate acid $\left(\mathrm{pyrH}, 0.37 ;{ }^{[45]} \mathrm{pyH}\right.$, $\left.5.25 ;^{[46]} \mathrm{imH}, 6.95^{[47]}\right)$. This reactivity trend is confirmed further by the crystallographic studies carried out on the isolated single crystals of compounds $\mathbf{1}-\mathbf{3}$. Moreover, addition of pyr to the aqueous solution of $\mathbf{1}$ led to the formation of the isostructural cluster $\mathbf{2}$ where pyrazine molecules 
are grafted on the vanadium oxide shell, whereas addition of im led to the formation of $[\mathrm{imH}]_{6}\left[\mathrm{~V}^{\mathrm{V}}{ }_{12} \mathrm{~V}^{\mathrm{IV}}{ }_{2} \mathrm{O}_{16}(\mu-\mathrm{O})_{10}\left(\mu_{3}-\mathrm{O}\right)_{10}\left(\mu_{3}-\mathrm{F}\right)_{2}(\mathrm{py})_{2}\right]$ instead. Freshly prepared crystalline material of compounds $\mathbf{1}-\mathbf{3}$ are soluble in $\mathrm{H}_{2} \mathrm{O}$ and DMSO. In general, compounds $\mathbf{1}-\mathbf{3}$ are stable during the course of our experimental investigations. However, prolonged stay in aqueous medium under air are further slowly oxidized which compromise the structural integrity of the $\left\{\mathrm{V}_{14}\right\}$ species.

Structural description of the compounds. X-ray diffraction analyses revealed three isostructural mixed-valent vanadium(V/IV) cages of the general formula, $\left[\mathrm{V}^{\mathrm{V}}{ }_{12} \mathrm{~V}^{\mathrm{IV}}{ }_{2} \mathrm{O}_{16}(\mu-\mathrm{O})_{10}\right.$ $\left.\left(\mu_{3}-\mathrm{O}\right)_{10}\left(\mu_{3}-\mathrm{F}\right)_{2}(\mathrm{~L})_{2}\right]^{6-}\left(\mathrm{L}=\right.$ py $(\mathbf{1}) ; \operatorname{pyr}(\mathbf{2})$; im (3); Figure 1). The overall structure $\left[\mathrm{V}_{14} \mathrm{O}_{36} \mathrm{~F}_{2} \mathrm{~L}_{2}\right]^{6-}$ anionic cluster can be described as an assembly of four discrete building blocks (denoted A-D; Figure 2) which differ in the geometry of vanadium. Fluoride templates the formation of two trinuclear building blocks (A) which consist of three edge-sharing $\mathrm{VO}_{5} \mathrm{~F}$ octahedra. The shared vertex position occupied by the fluoride ion was identified and characterized based on the observed thermal parameters and bond valence sum (BVS) calculations (vide infra). Within this trinuclear unit resides the $\mathrm{V}^{\mathrm{IV}}$ center specifically the octahedron furthest from the heterocyclic amine that connects the trinuclear building block with the two binuclear building blocks (B) as displayed in Figure 2. The building blocks type (B) and one trinuclear type (A) are bridged together via $\mu-\mathrm{O}$ and $\mu_{3}-\mathrm{O}$ bridges. On the external side of each trimer are grafted a $\mathrm{V}^{\mathrm{V}} \mathrm{O}_{4}$ tetrahedron $(\mathrm{C})$ which is bridged further with the trinuclear unit via a $\mathrm{V}^{\mathrm{V}} \mathrm{O}_{4} \mathrm{~L}$ trigonal bipyramid (D). One of the axial coordination sites of each trigonal bipyramid, is occupied by the N-donor ligand leading to the functionalization of the antipodal sites of the $\left\{\mathrm{V}_{14}\right\}$ cluster. 
The trinuclear units (A) are constructed by octahedral vanadium centers and connected by three $\mu-\mathrm{O}^{2-}$ moieties, with the $\mathrm{V}-\mathrm{O}$ bonds in the range of 1.931(1) - 1.938(1) $\AA$ and one terminal oxo group with a V-O bond in the range of 1.602(1) - 1.614(2) $\AA$. The corresponding V-F bond lengths span the range of 2.199(1) - 2.203(1) $\AA$ which is considerably elongated in comparison to the $\mathrm{V}-\mathrm{F}_{\mathrm{av}}$ of $1.996(1) \AA$ found in the $\left[\mathrm{V}^{\mathrm{IV}}{ }_{2} \mathrm{O}_{2} \mathrm{~F}_{4}(\mu-\mathrm{F})_{2}\left(\mathrm{OH}_{2}\right)_{2}\right]^{2-}$ starting material, due to the trans influence of the terminal $\mathrm{V}-\mathrm{O}$ bond; this is expected for $\mathrm{V}-\mathrm{O} / \mathrm{F}$ units while the distances are in agreement with previously reported data obtained from polyoxovanadate clusters that incorporate $\mathrm{F}$ atoms. ${ }^{[7 \mathrm{~d}, 12 \mathrm{~b}]}$ In the case of square planar building blocks (B) the relevant distances are 1.893(1) - 1.896(1) and 1.603(1) - 1.608(1) Å. The observed V-O distances are in agreement with previously reported data for other polyoxovanadate clusters. ${ }^{[\mathrm{d}, 9 \mathrm{~b}, 12 \mathrm{~b}]}$

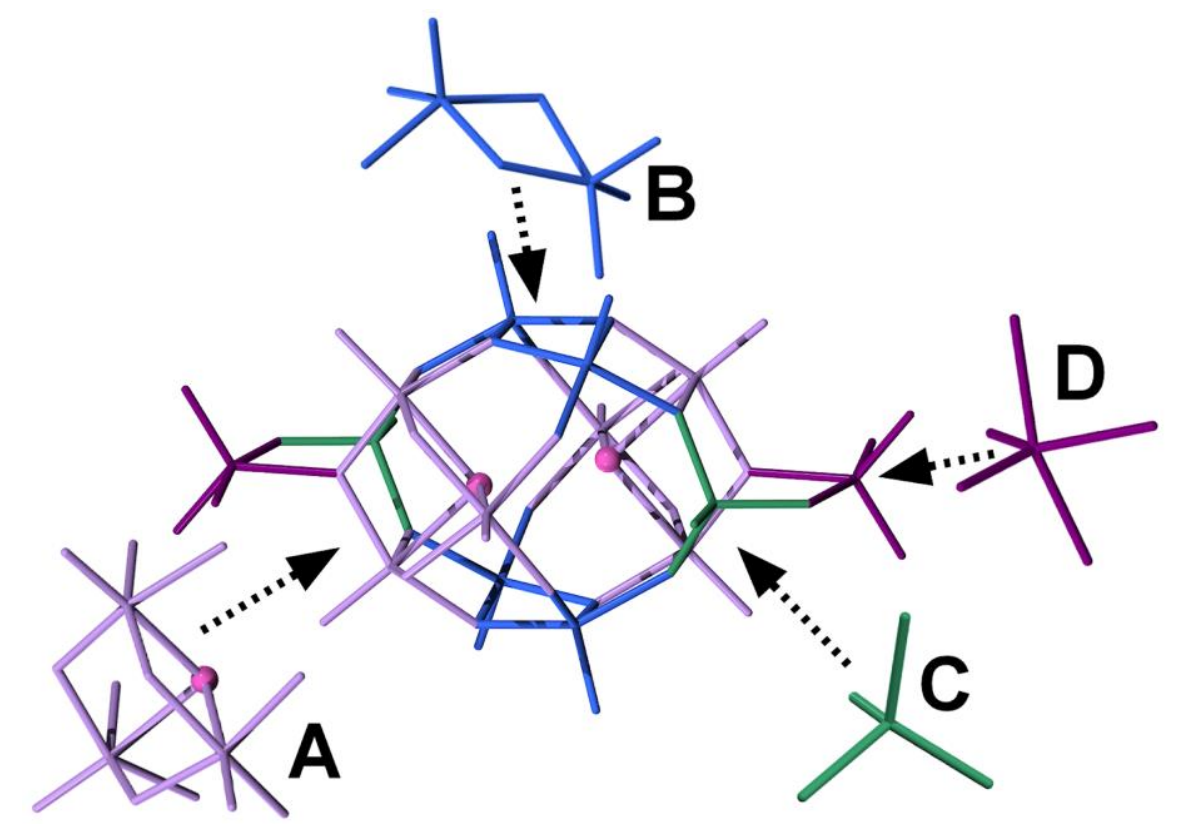

Figure 2. Representation of the assembly of the $\left[\mathrm{V}_{14} \mathrm{O}_{36} \mathrm{~F}_{2} \mathrm{~L}_{2}\right]^{6-}$ cluster. Generation of four different building blocks where the vanadium centers adopt octahedral (lavender, A), square pyramidal (lapis, B), tetrahedral (jade, C), and trigonal bipyramidal (aubergine, D) geometries. The fluoride anions are represented by pink spheres. 
Finally, the tetrahedral (C) and trigonal bipyramidal (D) moieties exhibited $\mathrm{V}-\mathrm{O}$ bonds in the range of $1.776(1)-1.783(1)$ and terminal $\mathrm{V}-\mathrm{O}$ bond $1.603(1)-1.608(1) \AA$ for the C's and $1.851(1)-1.931(1)$ and terminal V-O bond 1.622(1) - 1.628(1) $\AA$ for the D's, respectively. Finally, the observed V-N bond length found to be 2.148(2), 2.176(2) and 2.103(2) $\AA$ for compounds $\mathbf{1}, \mathbf{2}$ and $\mathbf{3}$, respectively.

The structural metrics were analyzed with BVS $^{[48]}$ calculations that revealed one reduced $\mathrm{V}^{\mathrm{IV}}$ center (V1; Figure S5) is located in each trinuclear building block (A), with $\mathrm{BVS}_{\mathrm{av}}$ values of 4.36, 4.32 and 4.40 for $\mathbf{1}, \mathbf{2}$, and $\mathbf{3}$, respectively. The remaining vanadium centers located in the trinuclear units (A), in the square planar binuclear units (B), the tetrahedral (C) and trigonal bipyramidal (D) units were found to be in the V oxidation state based on BVSav values of 4.96, 4.88, 4.87 and 4.94 for $\mathbf{1}, 4.96,4.89,4.85$ and 4.81 for $\mathbf{2}$, and $5.01,4.93,4.88$ and 4.80 for $\mathbf{3}$, respectively. The identification of the oxidation states of the vanadium centers was the result of the obtained from BVS, charge of the cluster in combination with the elemental analyses. In order to confirm further the spin states of the prepared clusters, we measured the room temperature magnetic moment for $\mathbf{1}-\mathbf{3}$ at $2.51,2.54$ and $2.56 \mu_{\mathrm{B}}$, respectively, which within experimental error nicely match the spin-only value for two fully uncoupled spins $\left(2.45 \mu_{\mathrm{B}}\right)$.

A noteworthy feature is the in situ of a plethora geometries adopted by the vanadium centers which gives rise to the formation of the family of $\left\{\mathrm{V}_{14}\right\}$ clusters. Additionally, it is worth noting that the ability to covalently functionalize the periphery of the clusters with nitrogen donor ligands provides a useful handle to elaborate these paramagnetic units into larger constructs with the inherent physical characteristics of the $\left\{\mathrm{V}_{14}\right\}$ unit intact. 
Mass spectrometry. In an effort to characterize further this family of clusters we employed high resolution ESI-MS to determine unambiguously the structural integrity and composition ${ }^{[49,50]}$ of the oxofluorovanadate species in solution. The ESI-MS studies were performed in solvent mixture of $\mathrm{H}_{2} \mathrm{O} / \mathrm{MeCN}$. The observation of a series of distribution envelopes is due to the existence of multiple charged states of the same moiety, resulting from the variable number of protons, counterions and solvent molecules. Additionally, vanadium clusters are generally susceptible to redox processes under the employed ionization conditions which induces partial fragmentation of the species. This type of behaviour is quite common in aqueous solution studies of POM compounds. ${ }^{[51]}$ The spontaneous or induced fragmentation is quite common approach adopted in the cases to reveal the stable constituents of the building block library which potentially led to the assembly of the species under investigation. ${ }^{[50]}$ In the region of high $\mathrm{m} / \mathrm{z}$ values we observed a series of distribution envelopes assigned to $2-$ charged species and correspond to the intact $\left\{\mathrm{V}_{14}\right\}$ cluster (Figure 3). The change of the oxidation state of the metal centers is due to the ionization and consecutive ion-transfer process of the charged species and has been observed previously in numerous occasions. ${ }^{[52]}$

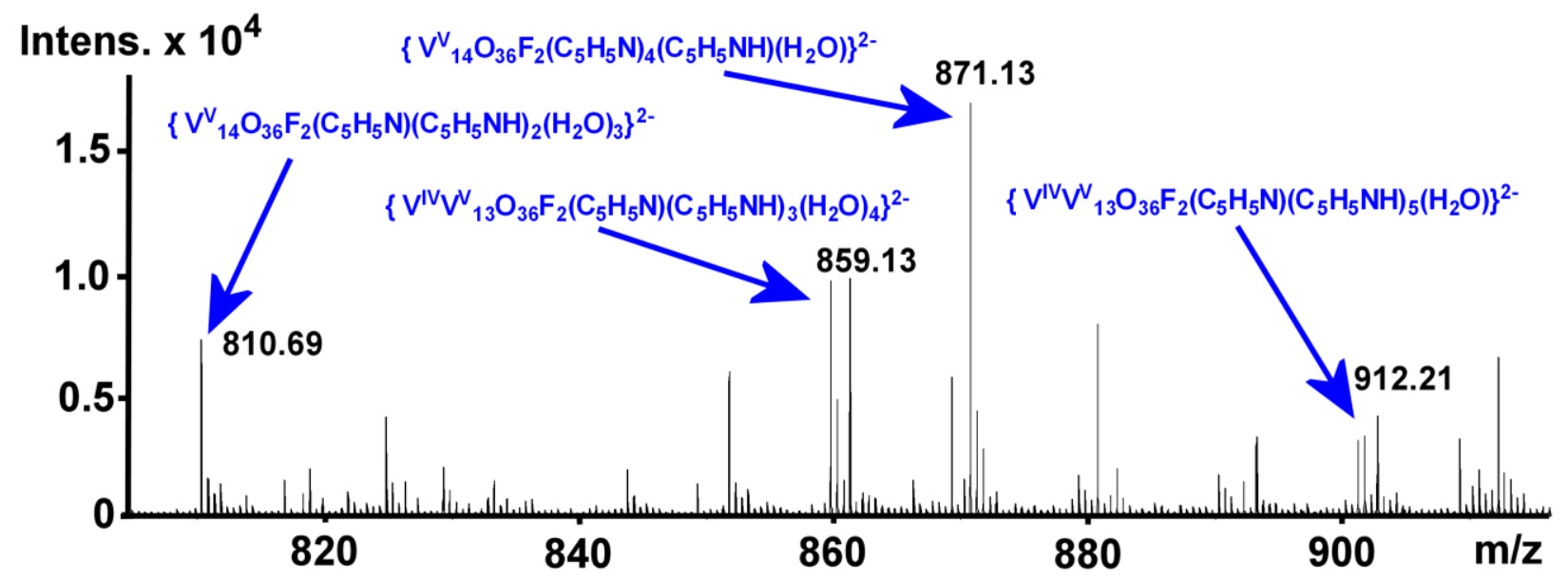

Figure 3. Negative ion ESI mass spectrum of 1 in $\mathrm{CH}_{3} \mathrm{CN}: \mathrm{H}_{2} \mathrm{O}(9: 1)$. 
Interestingly, the lower region of $\mathrm{m} / \mathrm{z}$ values $(\mathrm{ca} .450-800)$ revealed additional information in regard to the building block units that have been initially identified by X-ray diffraction analysis but also showing that the molecules fragment into the same building block. The distribution envelopes that have been tentatively assigned (Figures S6 and S7; Table S2) have been either one or more building blocks that form a fragment of the distinct cluster. The identification of the building blocks that appear in the mass spectrometry studies suggests the existence of an underlying sequential mechanism of assembly, where the building blocks of appropriate geometry forming first and subsequently self-organize into the structures that crystallise. More specifically, we observed a sequential removal of building blocks starting from the weakly attached trigonal bipyramids (D; Figure 2): $\left\{\mathrm{V}_{14}\right\}-\mathrm{D} \rightarrow\left\{\mathrm{V}_{13}\right\}$, followed by the gradual loss of the tetrahedral building blocks $\left(\mathrm{C}\right.$; Figure 2): $\left\{\mathrm{V}_{13}\right\}-2 \times \mathrm{D}-\mathrm{C} \rightarrow\left\{\mathrm{V}_{11}\right\}-\mathrm{C} \rightarrow\left\{\mathrm{V}_{10}\right\}$ (Figure 4; Table S2).

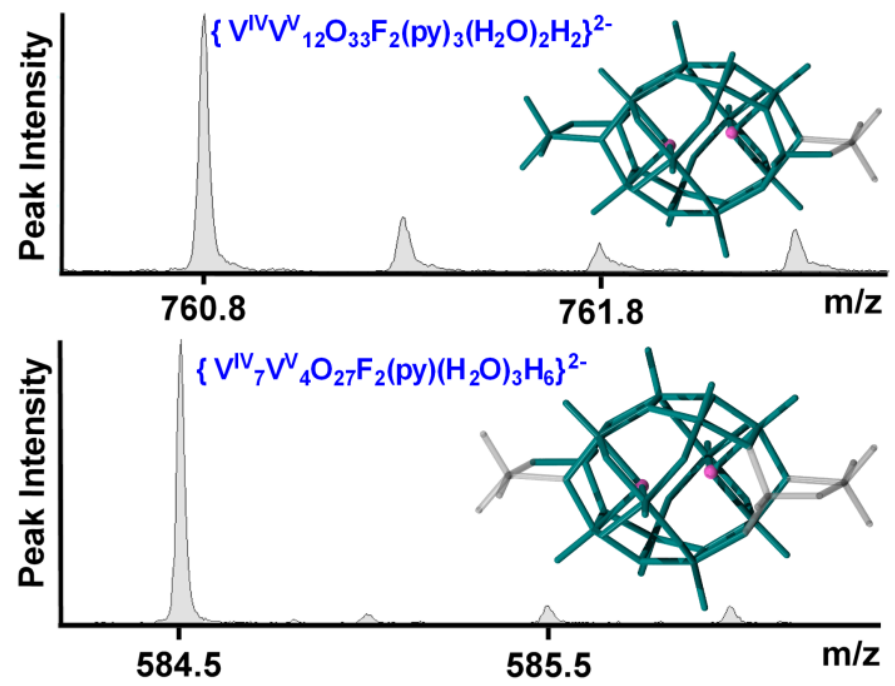

Figure 4. Illustration showing the experimental mass spectra of some prominent fragment ions observed during ESI-MS studies of 1. The structures above indicate the role of these fragments as building-blocks of the 'parent' $\left\{\mathrm{V}_{14}\right\}$ clusters. Colour scheme: F, pink spheres; remaining part 
of the $\left\{\mathrm{V}_{14}\right\}$ cluster, teal sticks; removed building blocks $2 \times \mathrm{D}$ and $1 \times \mathrm{C}$, light grey sticks (see Figure 2). $\mathrm{H}$ atoms and py ligands are omitted for clarity.

EPR spectroscopy. The presence of paramagnetic $\mathrm{V}^{\mathrm{IV}} \mathrm{d}^{1}$ ions in $\mathbf{1}$ was confirmed by EPR spectroscopy. The cluster dissolved in DMSO gave a spectrum at room temperature that was dominated by hyperfine coupling to the ${ }^{51} \mathrm{~V}$ nucleus $(I=7 / 2,99.75 \%$ natural abundance $)$ generating the hallmark 8-line pattern (Figure 5). Although ubiquitous for $\left[\mathrm{V}^{\mathrm{IV}} \mathrm{O}\right]^{2+}$ complexes, it is exceedingly rare to fluid solution spectra recorded on $\mathrm{V}^{\mathrm{IV}}$-containing POMs. ${ }^{[53,54]}$ In fact, to the best of our knowledge, this is the first fluid solution spectrum of an all-vanadium cluster. ${ }^{[55]}$ This spectrum is also identical to that for the starting material, [pyH $]_{2}\left[\mathrm{~V}^{\mathrm{IV}}{ }_{2} \mathrm{O}_{2} \mathrm{~F}_{4}(\mu-\mathrm{F})_{2}\left(\mathrm{OH}_{2}\right)_{2}\right]$ (Figure S3), ${ }^{[42]}$ except the cluster gives a slightly narrow line presumably a consequence of its lower solubility (less concentrated) and higher charge which discourages aggregation. Simulation of this spectrum yielded spin-Hamiltonian parameters $g_{\text {iso }}=1.961$ and a hyperfine coupling constant $A_{\text {iso }}=102 \times 10^{-4} \mathrm{~cm}^{-1}$, which are standard for a $\left[\mathrm{V}^{\mathrm{IV}} \mathrm{O}\right]^{2+}$ moiety. Most interestingly is that the spectrum shows no evidence for electronic coupling between the two $\mathrm{V}^{\mathrm{IV}}$ $\mathrm{d}^{1}$ centers in the cluster. This would be evidenced by a splitting of the eight lines in AB patterns by exchange coupling between the unpaired electrons (Eq. 2); the magnitude of it is wholly dependent on the strength of the exchange coupling relative to the hyperfine coupling constant. ${ }^{[56]}$ As such, we can provide an upper limit of $|J| \leq 10 \times 10^{-4} \mathrm{~cm}^{-1}$, as any additional splitting of the $m_{I}$ manifold is less than the experimental linewidth and obscured in this spectrum recorded at X-band frequency $(v=9.8 \mathrm{GHz})$. In addition to spin-spin coupling, there are examples of electron hopping from a $\mathrm{V}^{\mathrm{IV}}$ center to neighboring $\mathrm{V}^{\mathrm{V}}$ ions in many mixed-metal polyoxometalates giving rise to splitting of the hyperfine lines proportional to the number of 
adjacent $\mathrm{V}^{\mathrm{V}}$ ions. ${ }^{[3,54]}$ This phenomenon is temperature dependent and its manifestation is dictated by the $\mathrm{V}^{\mathrm{IV}}-\mathrm{O}-\mathrm{V}^{\mathrm{V}}$ angle where the efficiency through the bridging oxo ligand superexchange pathway is greatest when the angle is obtuse $\left(>140^{\circ}\right) \cdot{ }^{[54]}$ Interestingly, there is no evidence of electron hopping at room temperature in $\mathbf{1}$ despite there being four adjacent $\mathrm{V}^{\mathrm{V}}$ ions: two edge-shared octahedra, $\mathrm{V}-\mathrm{O}-\mathrm{V}=114^{\circ}$; two corner-shared polyhedra, $\mathrm{V}-\mathrm{O}-\mathrm{V}=138^{\circ}$ (Figure 1). This property has been previously observed in related $\mathrm{V}_{14}$ clusters with two $\mathrm{V}^{\mathrm{IV}}$ ions. $^{[2,57-59]}$

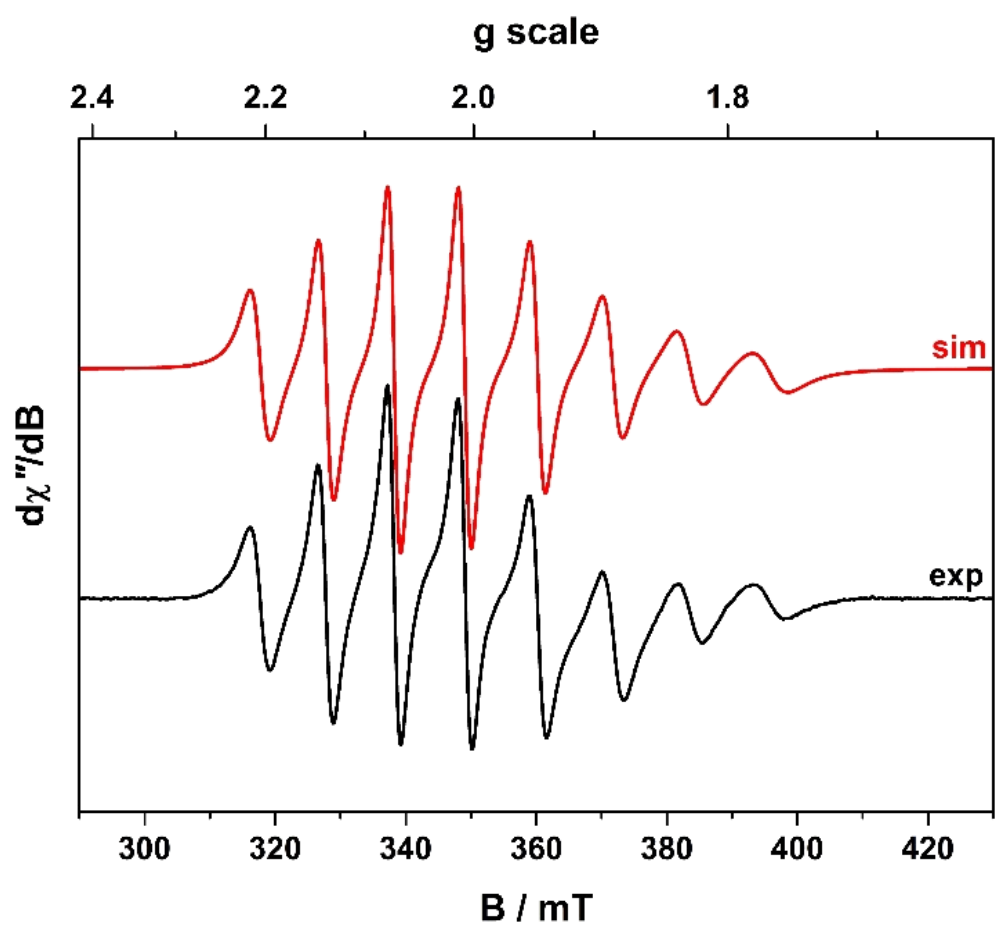

Figure 5. X-band EPR spectrum of 1 recorded in DMSO solution at $293 \mathrm{~K}$ (experimental conditions: frequency, $9.8082 \mathrm{GHz}$; power, $63 \mathrm{~mW}$; modulation, $0.4 \mathrm{mT}$ ). Experimental data are represented by the black line; simulation is depicted by the red trace.

The frozen solution spectrum of $\mathbf{1}$ is a DMSO/MeCN glass is typical of oxovanadium(IV) species (Figure 6). The linewidth in a frozen glass is narrower than the fluid solution spectrum, 
and again there is no evidence for exchange coupling or electron hopping giving additional splitting of the signal. Moreover, the absence of a signal at half-field for forbidden transition that derive from the triplet $(S=1)$ state of coupled $\mathrm{V}^{\mathrm{IV}}$ ions as has been observed in related systems. ${ }^{[60]}$ This is indicative of no exchange coupling (through bond) and a vanishingly small dipolar coupling (though space) whose magnitude is proportional to the cube of the interspin distance, ${ }^{[61]}$ which are separated by $6.5 \AA$ in $\mathbf{1}$ (vide supra). Not surprisingly the spectrum is very similar to that for the starting material, $[\mathrm{pyH}]_{2}\left[\mathrm{~V}^{\mathrm{IV}}{ }_{2} \mathrm{O}_{2} \mathrm{~F}_{4}(\mu-\mathrm{F})_{2}\left(\mathrm{OH}_{2}\right)_{2}\right]$ (Figure S4) although the latter exhibits features consistent with presence of a second paramagnetic entity which is common for oxovanadium(IV) species that can adopt a six solvent ligand or exchange solvent for a halide. ${ }^{[62]}$ Neither spectrum shows any indication of ${ }^{19} \mathrm{~F}(I=1 / 2,100 \%$ natural abundance $)$ hyperfine coupling.

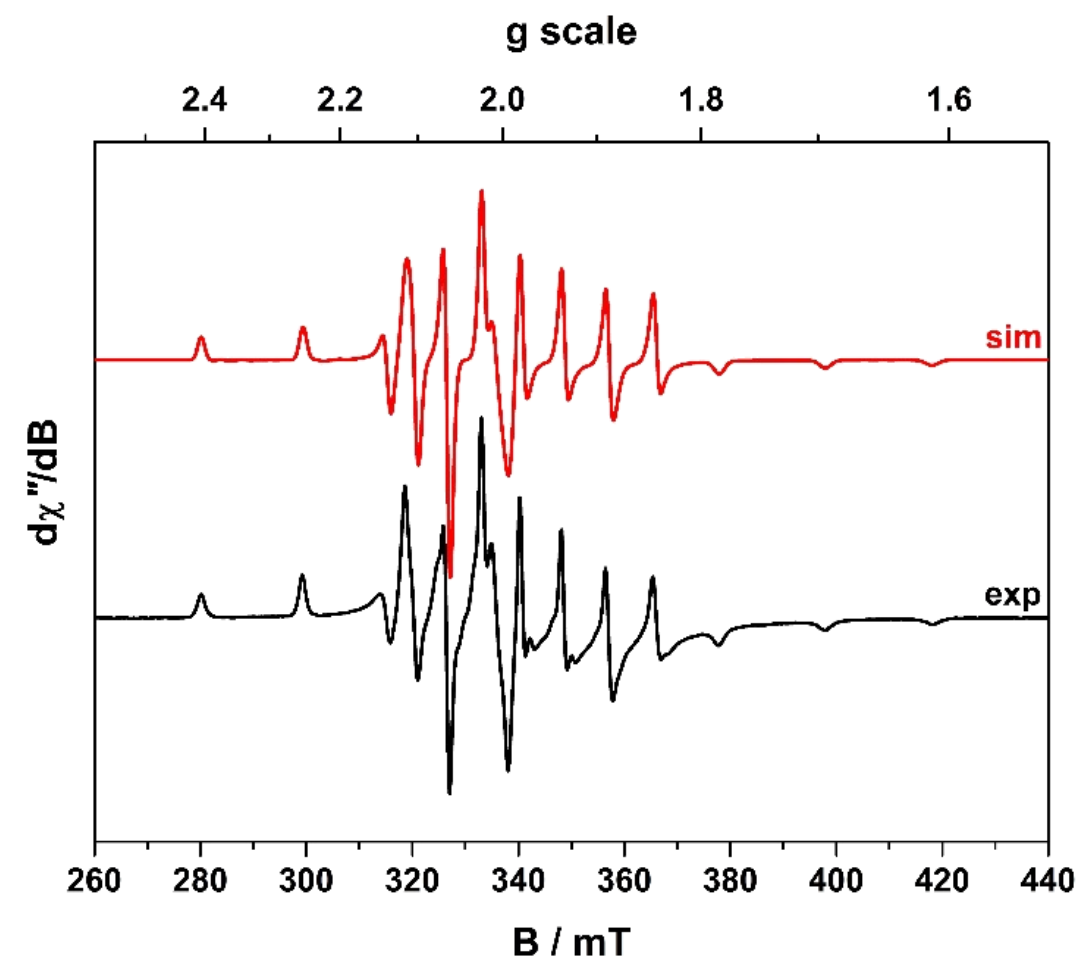


Figure 6. $\mathrm{X}$-band EPR spectrum of 1 recorded in $\mathrm{DMSO} / \mathrm{MeCN}$ solution at $130 \mathrm{~K}$ (experimental conditions: frequency, $9.4346 \mathrm{GHz}$; power, $0.63 \mathrm{~mW}$; modulation, $0.3 \mathrm{mT}$ ). Experimental data are represented by the black line; simulation is depicted by the red trace.

The spectrum has been simulation using the spin-Hamiltonian defined as in Eq. 4:

$$
\hat{H}=\mu_{\mathrm{B}} \mathbf{B} \cdot \mathbf{g} \cdot \mathbf{S}+\mathbf{S} \cdot \mathbf{A} \cdot \mathbf{I}
$$

where $\mathbf{g}$ and $\mathbf{A}$ are the $3 \times 3$ electron Zeeman and magnetic hyperfine interaction matrices, respectively. Oxovanadium(IV) EPR spectra are characterized as axial, with $g_{\|}\left(=g_{z}\right)<g_{\perp}\left(=g_{x}\right.$, $\left.g_{y}\right)<g_{\mathrm{e}}$, where the latter is the free electron, $g_{\mathrm{e}}=2.0023$. The hyperfine splitting is also axial with $A_{\|}>A_{\perp},{ }^{[63]}$ and these are the parameters that describe the ${ }^{2} \mathrm{~B}_{2}$ ground state $\left(\mathrm{d}_{x y}\right.$ orbital) of the oxovanadium(IV) unit possessing $C_{4 v}$ symmetry where the $z$-axis is parallel to the $\mathrm{V} \equiv \mathrm{O}$ bond. ${ }^{[64]}$ However, despite the approximate local $C_{4 v}$ symmetry of the oxovanadium(IV) ion, the presence of two edge-shared and two corner-shared polyhedra that constitute the $\mathrm{VO}_{4}$ equatorial plane means in principal these paramagnetic centers will trend closer to $C_{2 v}$, and exhibit orthorhombic symmetry, i.e. $g_{x} \neq g_{y}$ and $A_{x} \neq A_{y}$. Simulation of the spectrum yielded $g=(1.9726,1.9720$, $1.9291)$ and $A=(-65,-66,-177.4) \times 10^{-4} \mathrm{~cm}^{-1}$, revealing a negligible degree of orthorhombicity. Thus, EPR confirms 1 possesses two $\mathrm{V}^{\mathrm{IV}}$ ions with completely localized electrons with no exchange interaction $(J \approx 0)$.

DFT calculations. The electronic structure of 1 was examined using spin-unrestricted brokensymmetry (BS) DFT calculations at the B3LYP-ZORA level. The crystallographic coordinates were employed as there is negligible change between the solid state and geometry-optimized structure for these metal oxide clusters. Given the high charge of this anion, a water solvation 
shell was constructed defined by van der Waals radii of the constituent atoms. ${ }^{[65]}$ The addition of two electrons to a diamagnetic $\left\{\mathrm{V}_{14}\right\}$ cluster sees each one localized at either end of the molecule, specifically, $\mathrm{V} 1$ which sits at the center of a $\mathrm{VO}_{5} \mathrm{~F}$ octahedron that is linked to two edge-shared $\mathrm{VO}_{5} \mathrm{~F}$ octahedral (V4 and $\mathrm{V} 4 \mathrm{~A}$; Figure S5) and two corner-shared $\mathrm{VO}_{5}$ polyhedra (V5 and V5A; Figure S5). The latter are square pyramidal units that ultimately connect each $\left\{\mathrm{V}_{3} \mathrm{~F}\right\}$ cap, providing the bonding pathway that links the two unpaired electrons. There are two singly-occupied molecular orbitals (SOMO) that possess $56.3 \% \mathrm{~d}_{x y}$ character from $\mathrm{V} 1$ and $\mathrm{V} 1{ }^{\prime}$ (Figure 7). The strong $\sigma$ - and $\pi$-donating quality of the terminal oxo ligand ensures the nonbonding $\mathrm{d}_{x y}$ is the most stabilized in the $\mathrm{d}$ orbital manifold. ${ }^{[64]}$ This orbital engages in $\pi$-bonds with the four equatorial oxo ligands with bridge to adjacent $\mathrm{V}^{\mathrm{V}}$ ions in $\mathbf{1}$, and the SOMO is delocalized across to the $d_{x y}$ orbitals of each adjacent vanadium ion. The contribution is $7.1 \%$ from V4 and V4A and a markedly smaller 4.5\% from V5 and V5A because the larger $\mathrm{V}^{\mathrm{IV}}-\mathrm{O}-\mathrm{V}^{\mathrm{V}}$ angles of $138^{\circ}$ of the corner-shared polyhedra of the former provide better orbital overlap than their corner-shared counterparts $\left(\mathrm{V}^{\mathrm{IV}}-\mathrm{O}-\mathrm{V}^{\mathrm{V}}=114^{\circ}\right)$. Despite the bias toward the bonding pathway that links to one $\mathrm{V}^{\mathrm{IV}}$ center to the other, there is no electronic interaction between the two spins. This was proven experimentally with the absence of exchange coupling effects in the fluid and frozen solution EPR spectra (vide supra). The calculations nicely corroborate this observation of degenerate broken-symmetry solutions, one high-spin corresponding to ferromagnetically coupled spins - a spin-triplet $(S=1)$ - and the other the broken symmetry solution is the corresponding antiferromagnetically coupled spins to give a net singlet $(S=0)$ state. The two calculated solutions are near-degenerate, with the energy difference used to estimate the exchange coupling constant as determined by Eq. 1 to be a miniscule $0.9 \mathrm{~cm}^{-1}$. This 
is likely an overestimate given the limit of DFT to discriminate energy differences this small $\left(0.003 \mathrm{kcal} \mathrm{mol}^{-1}\right)$, such that like related $\left\{\mathrm{V}_{14}\right\}$ POMs,${ }^{[2,57-59]}$ the calculations confirm $J \approx 0$ in $\mathbf{1}$. The origin of this phenomenon is neatly revealed in the Mulliken spin population analysis which shows the distribution of the two unpaired spins in the cluster. As shown in Figure 7, the majority of the spin is located on V1 and V1' ions. However, vanadium-based POMs, as opposed those with heavier molybdenum and tungsten ions, possess highly ionic $\mathrm{V}-\mathrm{O}$ bonds that are readily polarized leading to spin density of the opposite sign ( $\beta$-spin) to be deposited on each oxo ligand. The polarization is strongest for the terminal oxo group as its bond distance is the shortest. As a consequence, the V-F bond is elongated (av. $2.204 \AA$ ) from the trans influence of the terminal oxo ligand thereby excluding any spin density from the fluoride ligand, therein no hyperfine coupling was observed. The polarization of the equatorial $\mathrm{V}-\mathrm{O}$ bonds in the cluster are the pathway for electronic communication. However pathway is constructed from an odd number of atoms which leads to deconstructive interference between the competing ferromagnetic and antiferromagnetic pathways. ${ }^{[66]}$ Therefore, where there should be a straightforward alternating "up-down" polarization of the bonds giving a preferred antiferromagnetic result is disrupted by the bridging oxo ligand in the center of the spin density plot in Figure 7 that bears no spin density on account of the cancellation of the $\alpha$-spin for one $\mathrm{V}^{\mathrm{IV}}$ ion and the opposing $\beta$-spin for the other. 

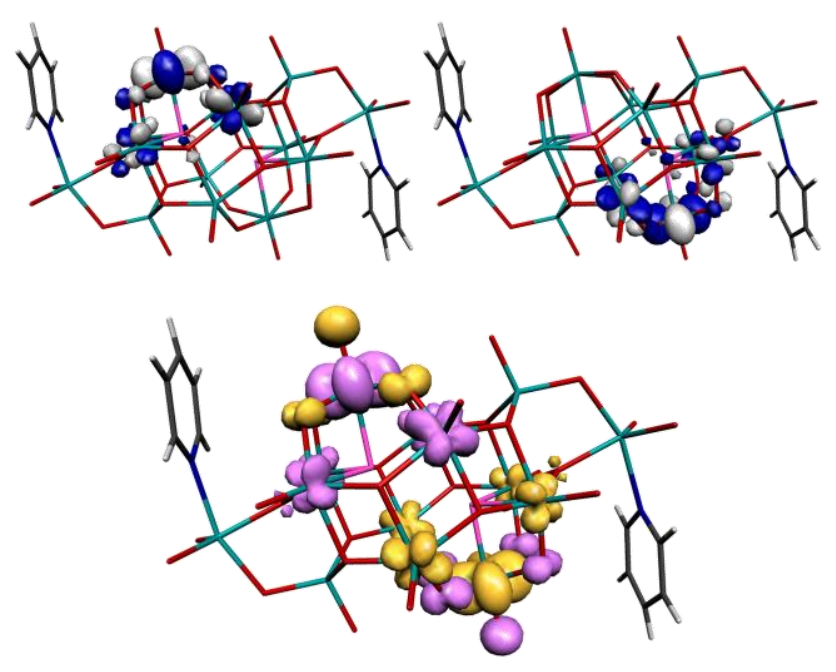

Figure 7. Top: Comparison of the two magnetic orbitals (SOMOs) in $\mathbf{1}$ from BS DFT calculations. Bottom: Mulliken spin density population ( $\alpha$-spin: lilac; $\beta$-spin: saffron).

In an effort to understand the physicochemical properties of these oxofluorovanadates, calculations were performed of the wholly inorganic component, $\left[\mathrm{V}_{14} \mathrm{O}_{36} \mathrm{~F}_{2}\right]^{6-}$. A natural bond orbital (NBO) population analysis revealed the $\mathrm{V}^{\mathrm{V}}$ ions to which the $\mathrm{N}$-donor ligands are bound (V3 and V3'; Figure S5) are the most electrophilic with the highest positive natural atomic charge of $1.558 \mathrm{el}$ (Figure 8). Moreover, the LUMO the $\left[\mathrm{V}_{14} \mathrm{O}_{36} \mathrm{~F}_{2}\right]^{6-}$ fragment is primarily localized on these electrophilic centers are constructed from the $\mathrm{d}_{z^{2}}$ AOs for each ion. Hence this site is poised to accept a lone pair from a donor atom, and although here we canvas three $\mathrm{N}$ donor ligands, there is scope to expand this family by diversifying the organic component in this functionalized hybrid system. The NBO analysis also shows that the $\mu_{3}-\mathrm{O}$ atoms are more basic than $\mu$-O counterparts, while the terminal oxygen atoms are the least basic (Figure 8). 

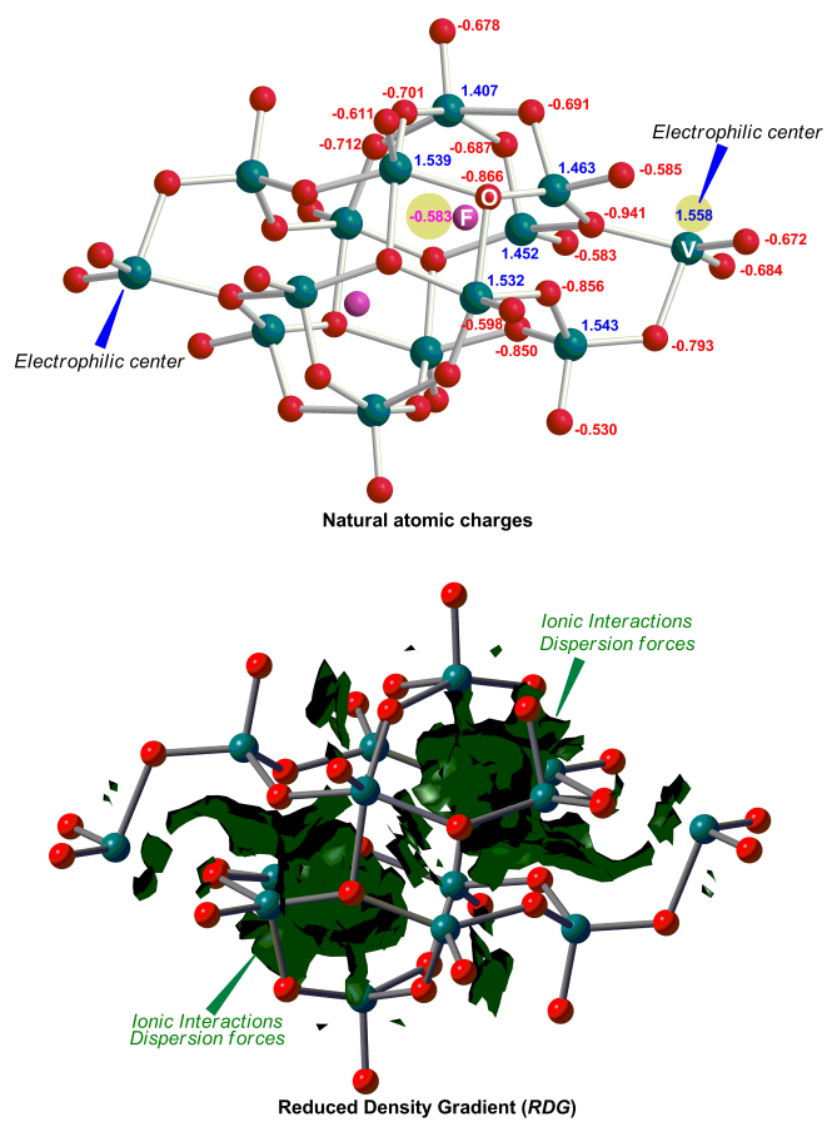

Figure 8. Top: Natural atomic charge distribution of the $\left[\mathrm{V}_{14} \mathrm{O}_{36} \mathrm{~F}_{2}\right]^{6-}$ cluster. Bottom: reduced density gradient $(R D G$, isosurface $=0.5 \mathrm{au})$.

The fluoride ion occupies a vertex of a cube consistent of the three vanadium atoms linked through three $\mu-\mathrm{O}$ atoms that constitute the trinuclear unit A (Figure. 9). The encapsulated ion resides at an average distance of $2.204 \AA$ from the metal ions, which is longer than the $\mathrm{V}-\mathrm{F}$ bonds in binuclear $\left[\mathrm{V}^{\mathrm{IV}}{ }_{2} \mathrm{O}_{2} \mathrm{~F}_{4}(\mu-\mathrm{F})_{2}\left(\mathrm{OH}_{2}\right)_{2}\right]^{2-}$, which was crystallized as the $\mathrm{Et}_{3} \mathrm{NH}^{+}$salt (Figure S1). The elongation is a consequence of the trans influence of the terminal oxo ligands on each vanadium ion. Nonetheless, the fluoride interacts strongly with this $\mathrm{V}_{3}(\mu-\mathrm{O})_{3}$ metallacycle; the energy of the interaction is estimated at $100 \mathrm{kcal} \mathrm{mol}^{-1}$. The calculated nucleus independent chemical shift (NICS) of a ghost atom as a function of its displacement of the midpoint of the 
six-membered $\mathrm{V}_{3}(\mu-\mathrm{O})_{3}$ metallocyclic ring is shown in Figure 9. The $\operatorname{NICS}_{\mathrm{zz}}(R)$ scan profile reveals that at the center of the ring and more judiciously at positions $1 \AA$ above and below (-1 $\AA),{ }^{[67]}$ the ghost atom has a negative NICS value diagnostic of $\sigma$-aromaticity in the $\mathrm{V}_{3}(\mu-\mathrm{O})_{3}$ ring.
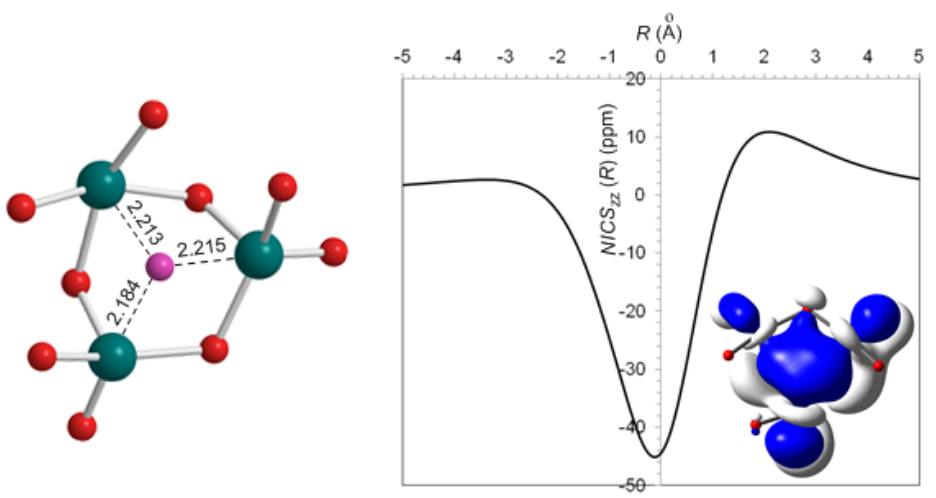

Figure 9. Depiction of trinuclear unit $\mathrm{A}$ interacting with the encapsulated $\mathrm{F}^{-}$ion and the $\operatorname{NICS}_{\mathrm{zz}}(R)$ scan curve for the six-membered $\mathrm{V}_{3}(\mu-\mathrm{O})_{3}$ metallacyclic ring and the in-plane delocalized $\sigma$-MO giving rise to $\sigma$-aromaticity.

To get insight into the nature of the interaction of the $\mathrm{F}^{-}$with the $\sigma$-aromatic $\mathrm{V}_{3}(\mu-\mathrm{O})_{3}$ ring, we calculated the reduced density gradient $(R D G)$ of the $\left[\mathrm{V}_{14} \mathrm{O}_{36} \mathrm{~F}_{2}\right]^{6-}$ cluster and analyzed the wave function of the $\left[\mathrm{V}_{3} \mathrm{O}_{9} \mathrm{~F}\right]^{4-}$ unit employing the Atoms In Molecules (AIM) approach. The $R D G$ plot is indicative for strong ionic interactions accompanied by dispersion forces (Figure 8). AIM analysis of $\nabla^{2} \rho$ reveals the existence of $(3,-1)$ bond critical points (BCPs) between the vanadium atom of the ring and the $\mathrm{F}^{-}$anion. ${ }^{[68]}$ The nature of the $\mathrm{V} \cdots \mathrm{F}$ interaction is evaluated from the calculating the electron density $\rho(\mathbf{r})$, the Laplacian of the electron density $\nabla^{2} \rho_{\mathrm{BC}}$, the energy density $H_{\mathrm{BCP}}$ and the ratio $H_{\mathrm{BCP}} / \rho_{\mathrm{BCP}}$, and the ratios $\left|V_{\mathrm{BCP}}\right| / G_{\mathrm{BCP}}$ and $G_{\mathrm{BCP}} / \rho_{\mathrm{BCP}}$ where $V_{\mathrm{BCP}}$ and $G_{\mathrm{BCP}}$ are the potential energy density and the kinetic energy density at the BCP, respectively. The bonding interaction is defined as ionic for $\left|V_{\mathrm{BCP}}\right| / G_{\mathrm{BCP}}<1$ and $\nabla^{2} \rho_{\mathrm{BCP}}>0$, whereas it is covalent for $H_{\mathrm{BCP}}>0$. For the $\mathrm{BCP}$ found between vanadium and fluoride centers, the values of these 
parameters are: $\rho(\mathbf{r})=0.043-0.047, \nabla^{2} \rho_{\mathrm{BCP}}=0.246-0.291, H_{\mathrm{BCP}}=0.006-0.008, H_{\mathrm{BCP}} / \rho_{\mathrm{BCP}}=$ $0.136-0.186, \mid V_{\mathrm{BCP}} / G_{\mathrm{BCP}}=0.852-0.894$ and $G_{\mathrm{BCP}} / \rho_{\mathrm{BCP}}=1.256-1.404$ (Table S3). Thus, since $\rho(\mathbf{r})<0.2$ au and $\nabla^{2} \rho_{\mathrm{BCP}}$ positive, the $\mathrm{V} \cdots \mathrm{F}$ interaction is mainly electrostatic in character. Moreover, the $G_{\mathrm{BCP}} / \rho_{\mathrm{BCP}}$ ratio exceeding unity indicating closed-shell interactions (dispersion forces) as portrayed by the $R D G$ plot. These closed-shell interactions correspond to unprecedented $\sigma-\mathrm{MO} /$ anion interactions that account for the charge transfer of $0.417|\mathrm{e}|$ from the $\mathrm{F}^{-}$to $\sigma-\mathrm{MO}$ of the $\mathrm{V}_{3}(\mu-\mathrm{O})_{3}$ metallacycle (donor/acceptor interactions).

\section{Conclusions}

In the present work we reported the synthesis and characterization of three new covalently functionalized, mixed-valent polyoxofluorovanadates: $[\mathrm{pyH}]_{6}\left[\mathrm{~V}_{12}^{\mathrm{V}} \mathrm{V}_{2}{ }_{2} \mathrm{O}_{16}(\mu-\mathrm{O})_{10}\left(\mu_{3}-\mathrm{O}\right)_{10}\left(\mu_{3}-\mathrm{F}\right)_{2}\right.$ (py) $\left.)_{2}\right] \cdot 10 \mathrm{H}_{2} \mathrm{O}$ (1), [pyH $]_{6}\left[\mathrm{~V}^{\mathrm{V}_{12}} \mathrm{~V}^{\mathrm{IV}}{ }_{2} \mathrm{O}_{16}(\mu-\mathrm{O})_{10}\left(\mu_{3}-\mathrm{O}\right)_{10}\left(\mu_{3}-\mathrm{F}\right)_{2}(\mathrm{pyr})_{2}\right]$ (2), and $[\mathrm{imH}]_{6}\left[\left(\mathrm{~V}^{\mathrm{V}}{ }_{12} \mathrm{~V}^{\mathrm{IV}}{ }_{2}\right.\right.$ $\left.\mathrm{O}_{16}(\mu-\mathrm{O})_{10}\left(\mu_{3}-\mathrm{O}\right)_{10}\left(\mu_{3}-\mathrm{F}\right)_{2}(\mathrm{im})_{2}\right] \cdot 2 \mathrm{H}_{2} \mathrm{O}(3)$. These clusters are the founding members of a family of oxofluorometalate organic-inorganic hybrids. Utilization of this new synthetic approach which involved the pre-functionalization of the vanadium precursors proved to be crucial for the covalent grafting of high nuclearity oxofluorometalate species in a single step process. Previously reported examples are mainly limited only to lower nuclearity functionalized species mainly due to inherent instabilities and side-reactions arising from the lack of coordination selectivity. Moreover, we discussed the impact of the encapsulated fluoride on the electronic structure of these clusters. Experimental data corroborated by theoretical and EPR studies revealed that the two unpaired electrons are confined to the antipodal sites of the cluster, where two sites have a paramagnetic $\mathrm{V}^{\mathrm{IV}}$ ion where no electronic coupling and magnetic communication is observed. This observed behaviour can be rationalized by the odd-numbered 
bond atom pathway between the vanadyl $\left(\mathrm{V}^{\mathrm{IV}} \mathrm{O}^{2+}\right)$ centers, where the spin density is annihilated at the mid-point of the bonding pathway which subsequently destroys the exchange interaction. The archetypal mixed-valent polyoxovanadate with the geneal formula $\left[\mathrm{XV}_{14} \mathrm{O}_{40}\right]^{8-}(\mathrm{X}=\mathrm{Al}, \mathrm{As}$, $\mathrm{Ge})$ is paramagnetic as the two excess electrons are localized to the vanadyl $\left(\mathrm{V}^{\mathrm{IV}} \mathrm{O}^{2+}\right)$ centers at either end of the cluster. ${ }^{[58,69]}$ This rather unusal arrangement, which is also the case here for $\mathbf{1}-$ 3, has been exploited for use as an electrical switch. ${ }^{[2,57]}$ The use of external stimuli to alter the magnetic properties of a molcule is central to the development of spintronic devices, including high density data storage in the form of molecular magnets as well as the hardware for quantum computing. ${ }^{[19]}$ The proof-of-concept has been neatly presented by Coronado and co-workers with $\left[\mathrm{GeV}_{14} \mathrm{O}_{40}\right]^{8-}$, who identified the barrier to spin coupling (uncoupled in the ground state; strongly antiferromagnetically coupled after application of an electric field) as the geomerty and ligation of the $\mathrm{V}^{\mathrm{V}}$ ions in the central belt that divides the cluster in two. ${ }^{[2,57]}$ Coronado and co-workers identified two problems that need addressing the next generation of materials, namely to function with significantly weaker electric fields and be less highly charged in order to control the electrical flow when in contact with electrodes. The $\left\{\mathrm{V}_{14}\right\}$ clusters developed here have the potential to overcome these experimental limitations as they likely have a lower barrier to spin relocalization because the difference between adjacent vanadium centers in the pathway that links the two $\mathrm{V}^{\mathrm{IV}}$ ions are more subtle. Secondly, the organic component offers a useful handle elaborate this design into assembled nanoscale constructs where the organic component provides a conduit to connect the prized magnetic properties of the inorganic component with a variety of external stimuli. Thus, this is a promising new platform upon which to develop future molecularbased spintronic devices. 


\section{Acknowledgments}

H.N.M would like to thank The University of Glasgow and the EPSRC (grants EP/L023652/1, EP/J015156/1) for the financial support as well as Prof. Leroy Cronin for providing access to the X-ray and ESI-MS facilities. We also thank the Research Promotional Foundation of Cyprus and the European Structural Funds for the purchase of EPR through

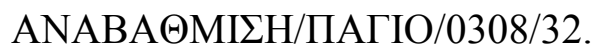

Electronic Supplementary Information (ESI) available: ESI-MS, EPR, TGA profiles, crystallographic data; calculated AIM parameters. See DOI: 10.1039/x0xx00000x

\section{References}

[1] H. N. Miras, J. Yan, D.-L. Long, L. Cronin, Chem. Soc. Rev. 2012, 41, 7403.

[2] S. Cardonna-Serra, J. M. Clemente-Juan, E. Coronado, A. Gaita-Ariño, N. Suaud, O. Svoboda, R. Bastardis, N. Guihéry, J. J. Palacios, Chem. Eur. J. 2015, 21, 763.

[3] a) H.-Y. Guo, T.-T. Zhang, P.-H. Lin, X. Zhang, X.-B. Cui, Q.-S. Huo, J.-Q. Xu, Cryst. Eng. Comm. 2017, 19, 265; b) E. Antonova, C. Näther, P. Kögerler, W. Bensch, Angew. Chem. Int. Ed. 2011, 50, 764.

[4] a) Y. Hayashi, Coord. Chem. Rev. 2011, 255, 2270; b) O. Linnenberg, P. Kozłowski, C. Besson, J. van Leusen, U. Englert, K. Yu. Monakhov, Cryst. Growth Des. 2017, 17, 2342.

[5] a) Y. Hayashi, Bull. Jpn. Soc. Coord. Chem. 2015, 66, 12; b) P. Kozłowski, A. NotarioEstévez, C. de Graaf, X. López, K. Yu. Monakhov, Phys. Chem. Chem. Phys., 2017, 19, 29767.

[6] A. Müller, R. Rohlfing, A.-L. Barra, D. Gatteschi, Adv. Mater. 1993, 5, 915. 
[7] a) D. Hou, K. S. Hagen, C. L. Hill, J. Am. Chem. Soc. 1992, 114, 5864; b) A. Müller, E. Krickemeyer, M. Penk, H.-J. Walberg, H. Bögge, Angew. Chem. Int. Ed. 1987, 26, 1045;

c) A. Müller, M. Penk, E. Krickemeyer, H. Bögge, H.-J. Walberg, Angew. Chem. Int. Ed. 1988, 27, 1719; d) A. Müller, R. Rohlfing, E. Krickemeyer, H. Bögge, Angew. Chem. Int. Ed. 1993, 32, 909.

[8] a) A. Müller, J. Meyer, H. Bögge, A. Stammler, A. Botar, Chem. Eur. J. 1998, 4, 1388; b) A. Müller, R. Rohlfing, J. Döring, M. Penk, Angew. Chem. Int. Ed. 1991, 30, 588.

[9] a) J. Forster, B. Rösner, R. H. Finke, L. C. Nye, I. Ivanovic-Burmazovic, K. Kastner, J. Tucher, C. Streb, Chem. Sci. 2013, 4, 418; b) K. Okaya, T. Kobayashi, Y. Koyama, Y. Hayashi, K. Isobe, Eur. J. Inorg. Chem. 2009, 5156.

[10] C. Streb, in Structure and Bonding in Molecular Vanadium Oxides: From Templates via Host-Guest Chemistry to Applications, Springer, Berlin, Heidelberg, 2017, pp. 1-17.

[11] L. Chen, F. Jiang, Z. Lin, Y. Zhou, C. Yue, M. Hong, J. Am. Chem. Soc. 2005, 127, 8588.

[12] a) Y. Kikukawa, T. Yokoyama, S. Kashio, Y. Hayashi, J. Inorg. Biochem. 2015, 147, 221; b) K. Yu. Monakhov, O. Linnenberg, P. Kozłowski, J.van Leusen, C. Besson, T. Secker, A. Ellern, X. López, J. M. Poblet, P. Kögerler, Chem. Eur. J. 2015, 21, 2387.

[13] a) E. Kemnitz, Catal. Sci. Technol. 2015, 5, 786; b) E. Kemnitz, S. Coman, in New Materials for Catalytic Applications (Eds.: V. I. Parvulescu, E. Kemnitz), Elsevier, Amsterdam, The Netherlands, 2016, pp. 133-191; c) B. L. Pagenkopf, E. M. Carreira, Chem. Eur. J. 1999, 5, 3437.

[14] N. F. Stephens, M. Buck, P. Lightfoot, J. Mater. Chem. 2005, 15, 4298.

[15] T. Mahenthirarajah, Y. Li, P. Lightfoot, Inorg. Chem. 2008, 47, 9097. 
[16] a) W. Ouellette, V. Golub, C. J. O'Connor, J. Zubieta, Dalton Trans. 2005, 291; b) W. Ouellette, M. Hui, C. J. O'Connor, J. Zubieta, Inorg. Chem. 2006, 45, 7628; c) R. R. Ryan, S. H. Mastin, M. J. Reisfeld, Acta Crystallogr. Sect. B 1971, 27, 1270.

[17] a) D. W. Aldous, N. F. Stephens, P. Lightfoot, Dalton Trans. 2007, 2271; b) S. Jones, H. Liu, W. Ouellette, K. Schmidtke, C. J. O'Connor, J. Zubieta, Inorg. Chem. Commun. 2011, 13, 491; c) C. Ninclaus, D. Riou, G. Férey, Chem. Commun. 1997, 851; d) T. M. Smith, M. Tichenor, J. M. Vargas, C. J. O'Connor, J. Zubieta, Inorg. Chim. Acta 2011, 378, 250.

[18] a) S. Rostamzadehmansor, G. Ebrahimzadehrajaei, S. Ghammamy, K. Mehrani, L. Saghatforoush, J. Fluorine Chem. 2008, 129, 674; b) J. Spandl, I. Brüdgam, H. Z. Hartl, Z. Anorg. Allg. Chem. 2003, 629, 539.

[19] J. M. Clemente-Juan, E. Coronado, A. Gaita-Ariño, Chem. Soc. Rev. 2012, 41, 7464.

[20] M. C. Chakravorti, A. R. Sarkar, J. Fluorine Chem. 1976, 8, 421.

[21] a) J. C. Bertolini, J. Emerg. Med. 1992, 10, 163; b) D. Peters, R. Miethchen, J. Fluorine Chem. 1996, 79, 161; c) E. B. Segal, Chem. Health Saf. 2000, 7, 18.

[22] G. M. Sheldrick, Acta Crystallogr. Sect. A 1990, 46, 467.

[23] G. M. Sheldrick, Acta Crystallogr. Sect. A 2008, 64, 112.

[24] L. J. Farrugia, J. Appl. Cryst. 1999, 32, 837.

[25] R. C. Clark, J. S. Reid, Acta Crystallogr. Sect. A 1995, 51, 887.

[26] G. R. Hanson, K. E. Gates, C. J. Noble, M. Griffin, A. Mitchell, S. Benson, J. Inorg. Biochem. 2004, 98, 903.

[27] Standard Methods of Chemical Analysis, 6th ed., van Nostrand, Princeton, NJ, 1975.

[28] F. Neese, WIREs Comput. Molec. Sci. 2012, 2, 73. 
[29] a) A. D. Becke, J. Chem. Phys. 1993, 98, 5648; b) C. T. Lee, W. T. Yang, R. G. Parr, Phys. Rev. $B$ 1988, 37, 785 .

[30] D. A. Pantazis, X.-Y. Chen, C. R. Landis, F. Neese, J. Chem. Theory Comput. 2008, 4, 908.

[31] a) E. van Lenthe, J. G. Snijders, E. J. Baerends, J. Chem. Phys. 1996, 105, 6505; b) E. van Lenthe, A. van der Avoird, P. E. S. Wormer, J. Chem. Phys. 1998, 108, 4783; c) J. H. van Lenthe, S. Faas, J. G. Snijders, Chem. Phys. Lett. 2000, 328, 107.

[32] a) R. Ahlrichs, K. May, Phys. Chem. Chem. Phys. 2000, 2, 943; b) F. Weigend, R. Ahlrichs, Phys. Chem. Chem. Phys. 2005, 7, 3297.

[33] a) A. Klamt, J. Phys. Chem. 1995, 99, 2224; b) A. Klamt, V. Jonas, J. Chem. Phys. 1996, 105, 9972; c) A. Klamt, G. Schüürmann, J. Chem. Soc., Perkin Trans. 2 1993, 799.

[34] a) L. Noodleman, J. Chem. Phys. 1981, 74, 5737; b) L. Noodleman, D. A. Case, A. Aizman, J. Am. Chem. Soc. 1988, 110, 1001; c) L. Noodleman, E. R. Davidson, Chem. Phys. 1986, 109, 131; d) L. Noodleman, J. G. Norman, J. H. Osborne, A. Aizman, D. A. Case, J. Am. Chem. Soc. 1985, 107, 3418; e) L. Noodleman, C. Y. Peng, D. A. Case, J. M. Monesca, Coord. Chem. Rev. 1995, 144, 199.

[35] a) T. Soda, Y. Kitagawa, T. Onishi, Y. Takano, Y. Shigetu, H. Nagao, Y. Yoshioka, K. Yamaguchi, Chem. Phys. Lett. 2000, 319, 223; b) K. Yamaguchi, Y. Takahara, T. Fueno, in Applied Quantum Chemistry (Ed.: V. H. Smith), Reidel, Dordrecht, The Netherlands, 1986, p. 155.

[36] Molekel, Advanced Interactive 3D-Graphics for Molecular Sciences, Swiss National Supercomputing Center. https://ugovaretto.github.io/molekel/ 
[37] A. E. Reed, L. A. Curtiss, F. Weinhold, Chem. Rev. 1988, 88, 899; (b) F. Weinhold, in The Encyclopedia of Computational Chemistry, Vol. 3 (Ed.: P. v. R. Schleyer), Wiley, Chichester, 1988.

[38] M. J. Frisch, G. W. Trucks, H. B. Schlegel, G. E. Scuseria, M. A. Robb, J. R. Cheeseman, G. Scalmani, V. Barone, B. Mennucci, G. A. Petersson, H. Nakatsuji, M. Caricato, X. Li, H. P. Hratchian, A. F. Izmaylov, J. Bloino, G. Zheng, J. L. Sonnenberg, M. Hada, M. Ehara, K. Toyota, R. Fukuda, J. Hasegawa, M. Ishida, T. Nakajima, Y. Honda, O. Kitao, H. Nakai, T. Vreven, J. A. Montgomery, Jr., J. E. Peralta, F. Ogliaro, M. Bearpark, J. J. Heyd, E. Brothers, K. N. Kudin, V. N. Staroverov, R. Kobayashi, J. Normand, K. Raghavachari, A. Rendell, J. C. Burant, S. S. Iyengar, J. Tomasi, M. Cossi, N. Rega, J. M. Millam, M. Klene, J. E. Knox, J. B. Cross, V. Bakken, C. Adamo, J. Jaramillo, R. Gomperts, R. E. Stratmann, O. Yazyev, A. J. Austin, R. Cammi, C. Pomelli, J. W. Ochterski, R. L. Martin, K. Morokuma, V. G. Zakrzewski, G. A. Voth, P. Salvador, J. J. Dannenberg, S. Dapprich, A. D. Daniels, Ö. Farkas, J. B. Foresman, J. V. Ortiz, J. Cioslowski, D. J. Fox, Gaussian 09, Gaussian, Inc., Wallingford CT, 2009.

[39] Y. Zhao, D. G. Truhlar, J. Phys. Chem. A 2006, 110, 5121.

[40] P. v. R. Schleyer, C. Maerker, A. Dransfeld, H. Jiao, N. J. R. van Eikema Hommes, J. Am. Chem. Soc. 1996, 118, 6317.

[41] T. Lu, F. Chen, J. Comput. Chem. 2012, 33, 580.

[42] M. K. Chaudhuri, S. K. Ghosh, J. Subramanian, Inorg. Chem. 1984, 23, 4439.

[43] J. B. Strong, G. P. A. Yap, R. Ostrander, L. M. Liable-Sands, A. L. Rheingold, R. Thouvenot, P. Gouzerh, E. A. Maatta, J. Am. Chem. Soc. 2000, 122, 639. 
[44] a) M. N. Corella Ochoa, H. N. Miras, D.-L. Long, L. Cronin, Chem. Eur. J. 2012, 18, 13743; b) H. N. Miras, M. Sorus, J. Hawkett, D. O. Sells, E. J. L. McInnes, L. Cronin, J. Am. Chem. Soc. 2012, 134, 6980.

[45] H. C. Brown, D. H. McDaniel, O. Häfliger, in Determination of Organic Structures by Physical Methods (Eds.: E. A. Braude, F. C. Nachod), Academic Press, New York, 1955, pp. 567-662.

[46] R. Linnell, J. Org. Chem. 1960, 25, 290.

[47] H. Walba, R. W. Isensee, J. Org. Chem. 1961, 26, 2789.

[48] I. D. Brown, D. Altermatt, Acta Crystallogr. Sect. B 1985, 41, 244.

[49] a) H. N. Miras, D.-L. Long, P. Kögerler, L. Cronin, Dalton Trans. 2008, 214; b) H. N. Miras, E. F. Wilson, L. Cronin, Chem. Commun. 2009, 1297; c) H.-Y. Zang, J.-J. Chen, D.L. Long, L. Cronin, H. N. Miras, Adv. Mater. 2013, 25, 6245.

[50] H. N. Miras, D. Stone, D.-L. Long, E. J. L. McInnes, P. Kögerler, L. Cronin, Inorg. Chem. 2011, 50, 8384 .

[51] E. F. Wilson, H. N. Miras, M. H. Rosnes, L. Cronin, Angew. Chem. Int. Ed. 2011, 50, 3720.

[52] a) H. N. Miras, D. J. Stone, E. J. L. McInnes, R. G. Raptis, P. Baran, G. I. Chilas, M. P. Sigalas, T. A. Kabanos, L. Cronin, Chem. Commun. 2008, 4703; b) H. Zang, A. Surman, D. Long, L. Cronin, H. N. Miras, Chem. Commun. 2016, 52, 9109.

[53] a) E. Cadot, M. Fournier, A. Tézé, G. Hervé, Inorg. Chem. 1996, 35, 282; (b) S. P. Harmalker, M. T. Pope, J. Phys. Chem. 1978, 82, 2823; b) S. P. Harmalker, M. T. Pope, J. Am. Chem. Soc. 1981, 103, 7381; c) C. W. Lee, H. So, K. R. Lee, Bull. Korean Chem. Soc. 1986, 7, 39; d) C. W. Lee, H. So, K. R. Lee, Bull. Korean Chem. Soc. 1986, 7, 108; e) M. 
M. Mossoba, C. J. O'Connor, M. T. Pope, E. Sinn, G. Hervé, A. Tézé, J. Am. Chem. Soc. 1980, 102, 6864.

[54] S. P. Harmalker, M. A. Leparulo, M. T. Pope, J. Am. Chem. Soc. 1983, 103, 4286.

[55] K. Y. Monakhov, W. Bensch, P. Kögerler, Chem. Soc. Rev. 2015, 44, 8443.

[56] B. M. Sawant, A. L. W. Shroyer, G. R. Eaton, S. S. Eaton, Inorg. Chem. 1982, 21, 1093.

[57] S. Cardonna-Serra, J. M. Clemente-Juan, A. Gaita-Ariño, N. Suaud, O. Svoboda, E. Coronado, Chem. Commun. 2013, 49, 9621.

[58] a) A. Müller, J. Döring, M. I. Khan, V. Wittneben, Angew. Chem. Int. Ed. 1991, 30, 210; b) L.-H. Bi, U. Kortz, M. H. Dickman, S. Nellutla, N. S. Dalal, B. Keita, L. Nadjo, M. Prinz, M. Neumann, J. Cluster Sci. 2006, 17, 143.

[59] N. Suaud, Y. Masaro, E. Coronado, J. M. Clemente-Juan, N. Guihéry, Dalton Trans. 2009, 5109.

[60] a) A. Aboukaïs, C. Haubtmann, J. J. André, C. Desquilles, M. Dourdin, I. MatthesJuventin-Andrieu, F. C. Aïssi, M. Guelton, J. Chem. Soc., Faraday Trans. 1995, 91, 1025; b) A.-L. Barra, D. Gatteschi, B. S. Tsukerblat, J. Döring, A. Müller, L.-C. Brunel, Inorg. Chem. 1992, 31, 5132; c) D. Gatteschi, B. Tsukerblat, A. L. Barra, L. C. Brunel, A. Müller, J. Döring, Inorg. Chem. 1993, 32, 2114.

[61] S. S. Eaton, K. M. More, B. M. Sawant, G. R. Eaton, J. Am. Chem. Soc. 1983, 105, 6560.

[62] S. S. Amin, K. Cryer, B. Zhang, S. K. Dutta, S. S. Eaton, O. P. Anderson, S. M. Miller, B. A. Reul, S. M. Brichard, D. C. Crans, Inorg. Chem. 2000, 39, 406.

[63] A. Abragam, B. Bleaney, Electron Paramagnetic Resonance of Transition Metal Ions, Clarendon Press, Oxford, 1970.

[64] C. J. Ballhausen, H. B. Gray, Inorg. Chem. 1962, 1, 111. 
[65] A. V. Marenich, C. J. Cramer, D. G. Truhlar, J. Phys. Chem. B 2009, 113, 6378.

[66] J. A. McCleverty, M. D. Ward, Acc. Chem. Res. 1998, 31, 842.

[67] A. C. Tsipis, Phys. Chem. Chem. Phys. 2009, 11, 8244.

[68] a) R. F. W. Bader, Atoms in Molecules: A Quantum Theory, Oxford University Press, Oxford, 1990; b) R. F. W. Bader, J. Phys. Chem. A 1998, 102, 7314; (b) D. Cremer, E. Kraka, Angew. Chem. Int. Ed. 1984, 23, 627; c) E. Espinosa, I. Alkorta, J. Elguero, E. Molins, J. Chem. Phys. 2002, 117, 5529.

[69] H. T. Evans, Jr, J. A. Konnert, Am. Mineral 1978, 63, 863. 